\title{
A Robust Circuit and Controller Parameters Identification Method of Grid-Connected Voltage Source Converters Using Vector Fitting Algorithm
}

\author{
Weihua Zhou, Member, IEEE, Raymundo E. Torres-Olguin, Fredrik Göthner, Jef Beerten, Senior Member, IEEE, \\ Mehdi Karbalaye Zadeh, Member, IEEE, Yanbo Wang, Senior Member, IEEE, and Zhe Chen, Fellow, IEEE
}

\begin{abstract}
This article presents a vector fitting (VF) algorithmbased robust circuit and controller parameters identification method for grid-connected voltage source converters (VSCs). The $d q$-domain impedance frequency responses (IFRs) of the VSCs are first measured using frequency scanning method, based on which the corresponding measured phasor-domain IFRs are calculated. Then, polynomial transfer functions are generated by applying the VF algorithm on the measured phasor-domain IFRs, from which the circuit and controller parameters, i.e., $L C L$ filter parameters, digital sampling time, current controller parameters, and phase-locked loop parameters, are identified. Influence of measurement noise on parameters identification accuracy and corresponding countermeasure to mitigate the adverse influence are also theoretically investigated. The proposed method is able to identify the circuit and controller parameters, when detailed parameters are missing due to industrial secrecy or parameters variation caused by operating condition change, temperature fluctuation, or aging. Effectiveness of the proposed circuit and controller parameters identification method is validated by theoretical demonstration, OPAL-RT-based real-time simulation, and experimental validation.
\end{abstract}

Index Terms-Impedance frequency responses, parameters identification, polynomial transfer function, vector fitting algorithm, voltage source converter.

\section{INTRODUCTION}

Renewable energy sources, such as wind power and solar power, have been increasingly penetrating into conventional

This work of Aalborg University was mainly supported by the project "Voltage Control and Protection for a Grid towards 100\% Power Electronics and Cable Network (COPE)" (Project No.: 880063), a 3-year project funded by ForskEL and EUDP in Denmark, and partially supported by the project "Center for Intelligent Electricity Distribution (CINELDI)" (Project No.: 257626/E20), an 8-year research center under the FME scheme in Norway. Portion of this work was presented at the ICPE-ECCE Asia, Busan, Korea, May 27-30, 2019 [1]. (Corresponding author: Zhe Chen.)

W. Zhou was with the Department of Energy Technology, Aalborg University, 9220 Aalborg, Denmark. He is now with the Department of Electrical Engineering, KU Leuven, 3001 Leuven, Belgium, and also with EnergyVille, 3600 Genk, Belgium (e-mail: weihua.zhou@kuleuven.be).

R. E. Torres-Olguin is with the SINTEF Energy Research Institute, 7034 Trondheim, Norway (e-mail: raymundo.torres-olguin@sintef.no).

F. Göthner is with the Department of Electric Power Engineering, Norwegian University of Science and Technology, 7034 Trondheim, Norway (e-mail: fredrik.gothner@ntnu.no).

J. Beerten is with the Department of Electrical Engineering, KU Leuven, 3001 Leuven, Belgium, and also with EnergyVille, 3600 Genk, Belgium (email: jef.beerten@kuleuven.be).

M. Karbalaye Zadeh is with the Department of Marine Technology, Norwegian University of Science and Technology, 7491 Trondheim, Norway (e-mail: mehdi.zadeh@ntnu.no).

Y. Wang and Z. Chen are with the Department of Energy Technology, Aalborg University, 9220 Aalborg, Denmark (e-mail: ywa@et.aau.dk; zch@et.aau.dk). power systems [2]. Grid-connected voltage source converters (VSCs), as the power electronic interface, are widely used to transmit the generated electrical energy into utility grid [3], [4]. It's important to know the accurate circuit and controller parameters of the VSCs to identify instability sources [5][9], to perform adaptive control [10]-[12], and to perform condition monitoring and fault diagnosis [13], [14]. However, subsystems of such a distributed power system are commonly provided by various manufacturers. Therefore, circuit and controller parameters of the VSCs are sometimes confidential due to industry secrecy and intellectual property rights [1], [15]. In addition, even if the nominal values are provided by the manufactures, parameters uncertainties of filter inductances and capacitances still exist due to manufacturing tolerance, operating condition variation, temperature fluctuation, and aging [10], [12], [16], [17].

Various methods have been proposed to estimate or identify the parameters of the VSCs [10], [11], [13], [14], [18]-[21]. The equivalent loss resistance between the VSC and grid, and both equivalent inductance and resistance between the VSC and grid are estimated based on evaluation of closedloop transient responses of the current controller in [18] and [19], respectively. In addition, the active and reactive powerbased model reference adaptive control approach is used to estimate the equivalent inductance and resistance between the VSC and grid in [11]. Furthermore, the parameters of grid equivalent, AC filter, switching, and conduction loss resistance are estimated using the extended harmonic domain in [20]. However, the parameter estimation methods proposed in [11], [18]-[20] are relatively complicated. In addition, only physical parameters can be estimated, whereas the controller parameters are still missing. Pseudorandom binary sequence is injected into current control loop of the VSCs, and the impedance information is obtained by performing the fast Fourier transform (FFT) on perturbed terminal voltage and output current, from which the parameters of $L$ filter, transmission line impedance, and $L C L$ filter are identified in [10], [13], and [14] respectively. The pseudorandom binary sequence-based parameter identification methods are relatively easy, since the perturbation signal is only composed of two electrical levels, i.e., $+1 \mathrm{~V}$ and $-1 \mathrm{~V}$, which can be easily generated with a modest digital controller. However, only circuit parameters instead of controller parameters can be identified. A two-step parameters identification method is proposed in [21], where step one uses a three-phase fault to identify all voltage loop 
parameters and proportional coefficient of current loop, and step two uses dc voltage reference jump disturbance to identify the integral coefficient of current loop and inductance of the $L$-filter. However, how to modify the two-step parameters identification method for $L C L$-filtered VSC is not explained in [21]. In addition, the implementation procedure is timeconsuming.

Circuit or controller parameters of the VSCs are extracted from terminal impedance frequency responses (IFRs) in [1], [7], [9], [22]. Specifically, the concept is originally presented in [7], where parameters of dc voltage controller, current controller, and phase-locked loop (PLL) are simultaneously identified by equalizing theoretical and measured terminal IFRs under the assumption that the control structure is known. However, filter parameters are assumed to be known. In addition, detailed parameters extraction procedure is missing, which cannot provide the guideline on how to linearize the nonlinear elements (e.g., digital time delay) to enforce the theoretical impedance transfer function to be in the same form of fitted impedance transfer function which is commonly a linear polynomial transfer function. In [9], [22], we developed the concept to further identify the $L C L$ filter parameters and digital sampling time of grid-side-current-controlled VSCs with capacitor current feedback active damping, where linearization of the digital time delay is one main focus. However, the method presented in [9], [22] is not robust, since influence of practical measurement noise on parameters identification accuracy and corresponding countermeasure to reduce the adverse influence are missing. The research gap is further filled in [1], where the adverse influence of measurement noise is weakened by fitting the measured IFRs with higher orders. However, only simple inner current control loop is investigated in [1], [9], [22]. How to further identify parameters of other controllers, e.g., PLL, should be further studied. In addition, further practical application of the identification results, e.g., controller parameters re-tuning for stability enhancement of the VSC-grid system, is missing in [1].

The frequency scanning method has widely been used to online measure grid impedance [23]-[27], and to online measure $d q$-domain IFRs of the VSCs [28]-[30]. The measured $d q$ domain IFRs are directly used for impedance-based stability criteria (IBSC) in [23], [24], [27], [29], [30]. Specifically, in [25], [28], parametric transfer functions are generated from the non-parametric IFRs using wideband system identification technique, based on which grid resistance, inductance, and capacitance are identified. In addition, discrete $d q$-domain IFRs of the VSCs are fitted into a parametric transfer function in [15], [31]-[33]. However, no circuit and controller parameters of the VSC are further identified in [15], [25], [28], [31]-[33]. Furthermore, the state-space model of the VSC is generated from phasor-domain IFRs using the vector fitting (VF) algorithm in [5], [6], [34], and from $d q$-domain IFRs using the matrix fitting (MF) algorithm in [35], respectively. However, the state variables of such a state-space representation are virtual, which indicates that actual inner dynamics cannot be revealed.

In order to further develop the identification algorithms proposed in [1], [7], [9]-[11], [13]-[15], [18]-[22], [25], [28],
[31]-[33], this article presents a robust method to identify circuit and controller parameters of the VSCs, i.e., $L C L$ filter parameters, the proportional coefficient of the current controller, PLL controller parameters, and digital sampling time, based on measured $d q$-domain IFRs of the VSCs. The $d q$-domain IFRs of the VSC are first obtained by the frequency scanning method explained in [36], from which the phasor-domain IFRs are calculated. A polynomial transfer function can be generated from the phasor-domain IFRs of VSC using the VF algorithm, from which the circuit and controller parameters are then identified. The proposed parameters identification method can be used to identify instability source, to perform adaptive controller re-tuning, and to perform monitoring and fault diagnosis. Main contributions of the article are explained as follows. 1) Effects of current control loop and PLL on the four components of the $d q$-domain impedance model of the VSC are investigated, which is able to simplify the parameters identification algorithm. 2) A separation method of current control loop-contributed and PLL-contributed $d q$-domain IFRs is presented, which is able to extract the current control loop-contributed impedance component. 3) An optimal order selection scheme of the Pade approximation for digital time delay under both grid current control (GCC) and converter current control (CCC) modes is presented, which facilitates to represent the impedance model of the VSC as a polynomial transfer function. 4) An adaptive order selection scheme of the fitted transfer function of the IFRs is presented, which is able to mitigate the adverse influence of measurement noise on parameters identification accuracy.

The rest of this article is organized as follows. Section II gives the theoretical background. The principle of the proposed circuit and controller parameters identification method is explained in Section III. Section IV provides the theoretical demonstration results, where the influence of measurement noise on parameters identification accuracy and corresponding countermeasure to mitigate the influence are also discussed. Real-time simulation verification based on OPAL-RT digital simulator and power-hardware-in-the-loop (PHiL)-based experimental validation are shown in Section V. Finally, the conclusion is drawn in Section VI.

\section{THEORETICAL BACKGROUND}

In this section, analytical expressions of impedance models of the grid-connected VSCs under both GCC and CCC modes are reviewed, where the relations among $d q$, sequence, and phasor-domain impedance models are explained. In addition, the principle of the VF algorithm is introduced.

\section{A. Analytical Expressions of the Impedance Models in DQ, Sequence, and Phasor-Domains}

Fig. 1(a) shows the configuration of a typical grid-connected VSC under GCC mode with PLL. Based on the derivation procedure of the $d q$-domain impedance model of the $L$-filtered VSC in [37], the control block diagram of the $L C L$-filtered VSC under GCC mode is shown in Fig. 1(b), where the matrix 


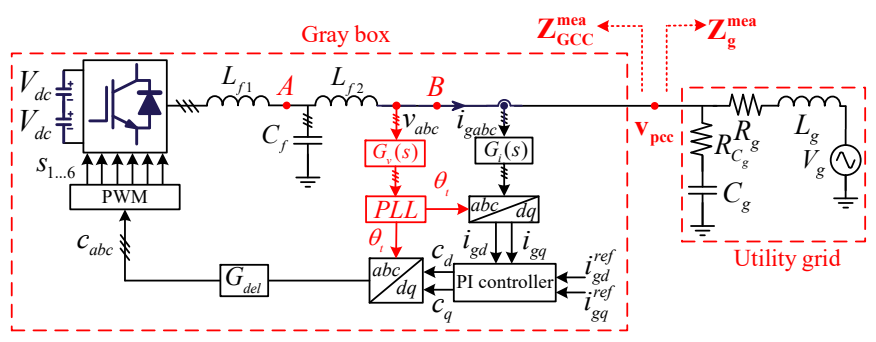

(a)

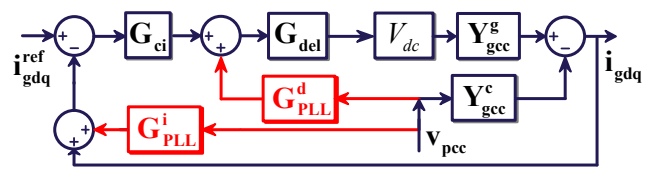

(b)

Fig. 1. Typical control strategy of a grid-connected VSC under GCC mode with inner current control loop and PLL. (a) One-line diagram. (b) Control block diagram [37].

representations are listed in the Appendix. The $d q$-domain impedance model can be derived from Fig. 1(b), shown as

$$
\begin{aligned}
\mathbf{Z}_{\mathbf{G C C}}=-\left.\frac{\mathbf{v}_{\mathbf{p c c}}}{\mathbf{i}_{\text {gdq }}}\right|_{\substack{\mathbf{i g d q} \\
\text { ref }=\mathbf{0}}} & (\mathbf{Y}_{\mathbf{g c c}}^{\mathbf{c}} \underbrace{-V_{d c} \mathbf{Y}_{\mathbf{g c c}}^{\mathbf{g}} \mathbf{G}_{\text {del }}\left(-\mathbf{G}_{\mathbf{c i}} \mathbf{G}_{\mathbf{P L L}}^{\mathbf{i}}+\mathbf{G}_{\mathbf{P L L}}^{\mathbf{d}}\right)}_{\text {The effect of PLL }})^{-\mathbf{1}} \\
& \cdot\left(\mathbf{I}+V_{d c} \mathbf{Y}_{\mathbf{g c c}}^{\mathbf{g}} \mathbf{G}_{\text {del }} \mathbf{G}_{\mathbf{c i}}\right) .
\end{aligned}
$$

If PLL dynamic is ignored, (1) can be simplified as

$$
\mathbf{Z}_{\mathbf{G C C}}^{\text {simp }}=\mathbf{Z}_{\text {gcc }}^{\mathrm{c}}+V_{d c} \mathbf{Z}_{\text {gcc }}^{\mathrm{c}} \mathbf{Y}_{\mathrm{gcc}}^{\mathrm{g}} \mathbf{G}_{\mathrm{del}} \mathbf{G}_{\mathbf{c i}}
$$

where $\mathbf{Z}_{\mathbf{G C C}}^{\text {simp }}=\left[Z_{G C C d d}^{s i m p}, Z_{G C C d q}^{s i m p} ; Z_{G C C q d}^{s i m p}, Z_{G C C q q}^{s i m p}\right]$. Furthermore, the corresponding sequence-domain impedance model $\mathbf{Z}_{\text {GCCpn }}^{\text {simp }}$ can be calculated as [38]

$$
\mathbf{Z}_{\mathbf{G C C p n}}^{\text {simp }}=\left[\begin{array}{cc}
Z_{G C C p p}^{\text {simp }} & Z_{G C C p n}^{s i m p} \\
Z_{G C C n p}^{\text {simp }} & Z_{G C C n n}^{\text {simp }}
\end{array}\right]=\mathbf{T} \mathbf{Z}_{\mathbf{G C C}}^{\text {simp }} \mathbf{T}^{-\mathbf{1}}
$$

where $\mathbf{T}=\frac{1}{\sqrt{2}}[1, j ; 1,-j]$. The phasor-domain impedance model $Z_{G C C}$ can then be derived as [39]

$$
Z_{G C C}=Z_{G C C p p}^{s i m p}\left(s-j \omega_{1}\right)=Z_{G C C n n}^{s i m p}\left(s+j \omega_{1}\right),
$$

where $\omega_{1}$ is the fundamental angular frequency. Specifically, $Z_{G C C}=Z_{G C C d d}^{s i m p}=Z_{G C C q q}^{s i m p}$ and $Z_{G C C d q}^{s i m p}=-Z_{G C C q d}^{s i m p}$. By substituting (38), (40), and (41) into (3), $Z_{G C C}$ can be derived as

$$
Z_{G C C}=\left(V_{d c} G_{c i} G_{d e l}+L_{f 1} s\right) /\left(1+L_{f 1} C_{f} s^{2}\right)+L_{f 2} s .
$$

If the current sensing point in Fig. 1(a) is moved from point $B$ to point $A$, the VSC is under CCC mode. Similarly, the $d q-$ domain impedance model can be derived as

$$
\begin{aligned}
\mathbf{Z}_{\mathbf{C C C}}= & \left(\left((\mathbf{Y}_{\mathbf{c c c}}^{\mathbf{c}} \underbrace{-V_{d c} \mathbf{Y}_{\mathbf{c c c}}^{\mathbf{g}} \mathbf{G}_{\mathbf{d e l}}\left(-\mathbf{G}_{\mathbf{c i}} \mathbf{G}_{\mathbf{P L L}}^{\mathbf{i}}+\mathbf{G}_{\mathbf{P L L}}^{\mathbf{d}}\right)}_{\text {The effect of PLL }})^{-\mathbf{1}}\right.\right. \\
& \left.\cdot\left(\mathbf{I}+V_{d c} \mathbf{Y}_{\mathbf{c c c}}^{\mathbf{g}} \mathbf{G}_{\mathbf{d e l}} \mathbf{G}_{\mathbf{c i}}\right)\right)^{-\mathbf{1}}+\mathbf{Z}_{\mathbf{C}_{\mathbf{f}}^{-1}}^{-\mathbf{1}}+\mathbf{Z}_{\mathbf{L}_{\mathbf{f} 2}} \cdot(6)
\end{aligned}
$$

The simplified $d q$-domain impedance model without considering PLL dynamic is shown as

$$
\mathbf{Z}_{\mathbf{C C C}}^{\operatorname{simp}}=\left(\left(\mathbf{Z}_{\mathbf{c c c}}^{\mathrm{c}}+V_{d c} \mathbf{Z}_{\mathbf{c c c}}^{\mathrm{c}} \mathbf{Y}_{\mathrm{ccc}}^{\mathrm{g}} \mathbf{G}_{\mathrm{del}} \mathbf{G}_{\mathbf{c i}}\right)^{-1}+\mathbf{Z}_{\mathbf{C}_{\mathbf{f}}}^{-1}\right)^{-1}+\mathbf{Z}_{\mathbf{L}_{\mathrm{f} 2}} \cdot(7)
$$

The phasor-domain impedance model can be calculated from the corresponding sequence-domain impedance model which is derived from (7) using (3), shown as

$$
Z_{C C C}=\left(\left(L_{f 1} s+V_{d c} G_{c i} G_{d e l}\right)^{-1}+C_{f} s\right)^{-1}+L_{f 2} s .
$$

The aforementioned relations among the $d q$, sequence, and phasor-domain impedance models lay the foundation of the proposed parameters identification method, as shown in Section III-B.

\section{B. VF Algorithm}

A series of discrete frequency responses of a single-inputsingle-output system, e.g., $g\left(\omega_{1}\right), g\left(\omega_{2}\right), \ldots, g\left(\omega_{N}\right)$, can be fitted by an s-domain transfer function using the VF algorithm, shown as [40]

$$
f(s)=\left(\sum_{i=0}^{m} B_{i} s^{i}\right) /\left(\sum_{i=0}^{m} A_{i} s^{i}\right)+E s,
$$

where $A_{i}$ and $B_{i}(i \in[0, m])$ are the coefficients of the denominator and numerator polynomials, respectively. $E$ is non-zero only if the order of numerator is higher than the order of denominator. The root-mean-square value of the fitting errors at the $N$ frequency points can be calculated as

$$
E_{f i t}=\sqrt{\frac{\sum_{i=1}^{N}\left(f\left(\omega_{i}\right)-g\left(\omega_{i}\right)\right)^{2}}{N}} .
$$

Note that the enhanced version of the VF algorithm, i.e., the MF algorithm, should be used to fit the frequency responses of a multi-input-multi-output system, which may be more timeconsuming and bring in heavier computation burdens [35]. In order to avoid the application of the MF algorithm in the proposed parameters identification method, the measured twodimensional $d q$-domain IFRs in form of (1) and (6) will be transferred into the one-dimensional phasor-domain IFRs in form of (5) and (8), as shown in Section III-B.

\section{PRoposed Circuit AND CONTROLler PARAMETERS IDENTIFICATION METHOD}

In this section, characteristics of the four components of the $d q$-domain admittance model are analyzed. On its basis, principle of the proposed parameters identification method is explained. Finally, the detailed implementation procedure of the proposed method is discussed.

\section{A. Characteristics of the DQ-Domain Admittance Model}

(1) can be reformulated as

$$
\mathbf{Z}_{\mathbf{G C C}}=\left(\mathbf{I}-\mathbf{G}_{\mathbf{G C C}}^{\mathbf{P L L}}\right)^{-1} \cdot \mathbf{Z}_{\mathbf{G C C}}^{\text {simp }},
$$

where $\mathbf{G}_{\mathbf{G C C}}^{\mathbf{P L}}$ depicts the effect of PLL on $\mathbf{Z}_{\mathbf{G C C}}$, shown as

$$
\mathbf{G}_{\mathbf{G C C}}^{\mathbf{P L L}}=\left[\begin{array}{cc}
0 & G_{G C C d q}^{P L L} \\
0 & G_{G C C q q}^{P L L}
\end{array}\right]=V_{d c} \mathbf{Z}_{\mathrm{gcc}}^{\mathbf{c}} \mathbf{Y}_{\mathrm{gcc}}^{\mathbf{g}} \mathbf{G}_{\mathrm{del}}\left(-\mathbf{G}_{\mathrm{ci}} \mathbf{G}_{\mathbf{P L L}}^{\mathbf{i}}+\mathbf{G}_{\mathbf{P L L}}^{\mathbf{d}}\right),
$$

where

$$
\begin{aligned}
& G_{G C C d q}^{P L L}=j\left(V_{c, q}^{s}+I_{g, q}^{s} G_{c i}\right) G_{P L L} G_{d e l} V_{d c} \\
& G_{G C L C q q}^{P L L}=\left(V_{c, d}^{s}+I_{g, d}^{s} G_{c i}\right) G_{P L L} G_{d e l} V_{d c} .
\end{aligned}
$$


Therefore, $d q$-domain admittance model $\mathbf{Y}_{\mathbf{G C C}}$ can be calculated based on (11), shown as

$\mathbf{Y}_{\mathbf{G C C}}=\left[\begin{array}{ll}Y_{G C C d d} & Y_{G C C d q} \\ Y_{G C C q d} & Y_{G C C q q}\end{array}\right]=\mathbf{Y}_{\mathbf{G C C}}^{\operatorname{simp}}\left(\mathbf{I}-\mathbf{G}_{\mathbf{G C C}}^{\mathbf{P L L}}\right)$,

where

$Y_{G C C d d}=Y_{G C C d d}^{\operatorname{simp}} \quad Y_{G C C q d}=Y_{G C C q d}^{\operatorname{simp}}$
$Y_{G C C d q}=Y_{G C C d q}^{\text {simp }}-\left(Y_{G C C d q}^{\text {simp }} G_{G C C q q}^{P L L}+Y_{G C C d d}^{\text {simp }} G_{G C C d q}^{P L L}\right)$
$Y_{G C C q q}=Y_{G C C q q}^{\text {simp }}-\left(Y_{G C C q q}^{\text {simp }} G_{G C C q q}^{P L L}+Y_{G C C q d}^{\text {simp }} G_{G C C d q}^{P L L}\right)$.

It is worthwhile noting that (15) agrees with the complex transfer function-based $d q$-domain admittance model in [41]. (15) shows that the $d-d$ and $q-d$ admittance components are not affected by PLL dynamics. The characteristics of the four components of $\mathbf{Y}_{\mathbf{C C C}}$ can also be analyzed in a similar way.

\section{B. Principle of the Proposed Parameters Identification Method}

The proposed method first identifies the parameters of current controller, $L C L$ filter, and digital sampling time, based on which PLL controller parameters are further identified.

1) Identification of Parameters of Current Controller, $L C L$ Filter, and Digital Sampling Time: Assume that $\mathbf{Y}_{\mathbf{G C C}}^{\mathrm{mea}}$ is the measured IFRs of $\mathbf{Y}_{\mathbf{G C C}}$. Based on (2) and (15), contribution of current control loop on $\mathbf{Y}_{\mathrm{GCC}}^{\mathrm{mea}}$, i.e., $\mathbf{Y}_{\mathrm{GCC}}^{\text {simpmea }}$, can be calculated as

$$
\begin{aligned}
\mathbf{Y}_{\mathbf{G C C}}^{\text {simpmea }}= & {\left[\begin{array}{cc}
Y_{G C C d d}^{\text {simpmea }} & -Y_{G C C q d}^{\text {simpmea }} \\
Y_{G C C q d}^{\text {simpmea }} & Y_{\text {GCCdd }}^{\text {simpmea }}
\end{array}\right]=\left[\begin{array}{cc}
0 & -1 \\
1 & 0
\end{array}\right] } \\
& \mathbf{Y}_{\mathbf{G C C}}^{\mathbf{m e a}}\left[\begin{array}{ll}
1 & 1 \\
0 & 0
\end{array}\right]+\mathbf{Y}_{\mathbf{G C C}}^{\mathbf{m e a}}\left[\begin{array}{ll}
1 & 0 \\
0 & 0
\end{array}\right] .
\end{aligned}
$$

Then, the measured phasor-domain IFRs can be calculated from $\mathbf{Y}_{\mathbf{G C C}}^{\text {simpmea }}$ using (3) and (4), which can further be fitted as a polynomial transfer function in the form of (9) using the $\mathrm{VF}$ algorithm. It can be seen that the extraction of the onedimensional phasor-domain IFRs avoids the direct application of the MF algorithm on the two-dimensional $\mathbf{Y}_{\mathbf{G C C}}^{\text {simpmea }}$. (5) should also be re-formulated as a polynomial transfer function to identify these parameters from the fitted transfer function. However, this reformulation is hindered by the digital time delay $G_{d e l}$ which can be approximated as a polynomial function using the Pade approximation, shown as [42]

$G_{d e l}=e^{-1.5 T_{s} s}=\frac{q_{l}\left(1.5 T_{s} s\right)^{l}+\ldots q_{i}\left(1.5 T_{s} s\right)^{i}+\ldots q_{0}}{p_{k}\left(1.5 T_{s} s\right)^{k}+\ldots p_{j}\left(1.5 T_{s} s\right)^{j}+\ldots p_{0}}$,

where $p_{j}=\frac{(l+k-j) ! k !}{j !(k-j) !}(j=0,1 \ldots, k)$ and $q_{i}=(-1)^{i} \frac{(l+k-i) ! l !}{i !(l-i) !}$ $(i=0,1 \ldots, l)$.

As stated in [5], the fitting error of (9) with order $m=5$ for a VSC is small enough, which will also be shown in Section IV-A. Therefore, appropriate values $l$ and $k$ should be selected to establish an equivalent polynomial transfer function of (5) with the orders of both numerator and denominator equal to 5. One possible Pade approximation of $G_{d e l}$ is to set $l=5$ and $k=3$ in (17), shown as

$G_{d e l}^{5-3}(s) \approx \frac{q_{5} T_{s}^{5} s^{5}+q_{4} T_{s}^{4} s^{4}+q_{3} T_{s}^{3} s^{3}+q_{2} T_{s}^{2} s^{2}+q_{1} T_{s} s+q_{0}}{p_{3} T_{s}^{3} s^{3}+p_{2} T_{s}^{2} s^{2}+p_{1} T_{s} s+p_{0}}$, where $p_{3}=405, p_{2}=4860, p_{1}=22680, p_{0}=40320$, $q_{5}=-45.5625, q_{4}=607.5, q_{3}=-4050, q_{2}=16200$, $q_{1}=-37800$, and $q_{0}=40320$. By substituting (18) into (5), $Z_{G C C}$ can be represented as

$Z_{G C C}=\frac{e_{5} s^{5}+e_{4} s^{4}+e_{3} s^{3}+e_{2} s^{2}+e_{1} s+e_{0}}{d_{5} s^{5}+d_{4} s^{4}+d_{3} s^{3}+d_{2} s^{2}+d_{1} s+d_{0}}+f s$,

where

$$
\begin{array}{ll}
d_{5}=p_{3} L_{f 1} C_{f} T_{s}^{3} & d_{4}=p_{2} L_{f 1} C_{f} T_{s}^{2} \\
d_{3}=p_{3} T_{s}^{3}+p_{1} L_{f 1} C_{f} T_{s} & d_{2}=p_{2} T_{s}^{2}+p_{0} L_{f 1} C_{f} \\
d_{1}=p_{1} T_{s} & d_{0}=p_{0},
\end{array}
$$

and

$$
\begin{aligned}
& e_{5}=k_{p i} V_{d c} q_{5} T_{s}^{5} \quad e_{4}=k_{p i} V_{d c} q_{4} T_{s}^{4}+p_{3} L_{f 1} T_{s}^{3} \\
& e_{3}=k_{p i} V_{d c} q_{3} T_{s}^{3}+p_{2} L_{f 1} T_{s}^{2} \quad e_{2}=k_{p i} V_{d c} q_{2} T_{s}^{2}+p_{1} L_{f 1} T_{s} \\
& e_{1}=k_{p i} V_{d c} q_{1} T_{s}+p_{0} L_{f 1} \quad e_{0}=k_{p i} V_{d c} q_{0} \quad f=L_{f 2} .
\end{aligned}
$$

By equalizing (19) and (9) with $m=5$, i.e., $f=E, d_{i}=A_{i}$ $(i \in[0,5])$, and $e_{j}=B_{j}(j \in[0,5])$, the circuit and controller parameters can be identified as

$$
\begin{aligned}
L_{f 2}^{i d e n} & =E \quad k_{p i}^{i d e n}=\frac{B_{0}}{A_{0} V_{d c}} \quad T_{s}^{i d e n}=\frac{16 A_{1}}{9 A_{0}} \\
L_{f 1}^{i d e n} & =\frac{B_{1}}{A_{0}}+\frac{15 k_{p i}^{i d e n} V_{d c} T_{s}^{i d e n}}{16} \\
C_{f}^{i d e n} & =\frac{A_{2}}{A_{0} L_{f 1}^{i d e n}}-\frac{27 T_{s}^{i d e n^{2}}}{224 L_{f 1}^{i d e n}} .
\end{aligned}
$$

Different from GCC mode, no matter what values are selected for $l$ and $k$ in (17) for CCC mode, the order of the numerator is always lower than the order of the denominator in the equivalent polynomial transfer function of (8). To establish an equivalent polynomial transfer function of (8) similar with (9) where $m=5$, besides the Pade approximation in (18), another Pade approximation with $l=k=4$ can be used, shows as

$$
G_{d e l}^{4}-4(s) \approx \frac{q_{4}^{\prime} T_{s}^{4} s^{4}+q_{3}^{\prime} T_{s}^{3} s^{3}+q_{2}^{\prime} T_{s}^{2} s^{2}+q_{1}^{\prime} T_{s} s+q_{0}^{\prime}}{p_{4}^{\prime} T_{s}^{4} s^{4}+p_{3}^{\prime} T_{s}^{3} s^{3}+p_{2}^{\prime} T_{s}^{2} s^{2}+p_{1}^{\prime} T_{s} s+p_{0}^{\prime}},
$$

where $p_{4}^{\prime}=121.5, p_{3}^{\prime}=1620, p_{2}^{\prime}=9720, p_{1}^{\prime}=30240, p_{0}^{\prime}=$ $40320, q_{4}^{\prime}=121.5, q_{3}^{\prime}=-1620, q_{2}^{\prime}=9720, q_{1}^{\prime}=-30240$, and $q_{0}^{\prime}=40320$.

On one hand, by substituting (18) into (8), $Z_{C C C}$ can be represented as

$Z_{C C C}=\frac{b_{5} s^{5}+b_{4} s^{4}+b_{3} s^{3}+b_{2} s^{2}+b_{1} s+b_{0}}{a_{6} s^{6}+a_{5} s^{5}+a_{4} s^{4}+a_{3} s^{3}+a_{2} s^{2}+a_{1} s+a_{0}}+c s$,

where

$$
\begin{aligned}
& a_{6}=k_{p i} V_{d c} q_{5} C_{f} T_{s}^{5} \quad a_{5}=\left(k_{p i} V_{d c} q_{4} T_{s}^{4}+p_{3} L_{f 1} T_{s}^{3}\right) C_{f} \\
& a_{4}=\left(k_{p i} V_{d c} q_{3} T_{s}^{3}+p_{2} L_{f 1} T_{s}^{2}\right) C_{f} \\
& a_{3}=p_{3} T_{s}^{3}+k_{p i} V_{d c} q_{2} C_{f} T_{s}^{2}+p_{1} L_{f 1} C_{f} T_{s} \\
& a_{2}=p_{2} T_{s}^{2}+k_{p i} V_{d c} q_{1} C_{f} T_{s}+p_{0} L_{f 1} C_{f} \\
& a_{1}=p_{1} T_{s}+k_{p i} V_{d c} q_{0} C_{f} \quad a_{0}=p_{0}
\end{aligned}
$$

and

$$
\begin{aligned}
& b_{5}=k_{p i} V_{d c} q_{5} T_{s}^{5} \quad b_{4}=k_{p i} V_{d c} q_{4} T_{s}^{4}+p_{3} L_{f 1} T_{s}^{3} \\
& b_{3}=k_{p i} V_{d c} q_{3} T_{s}^{3}+p_{2} L_{f 1} T_{s}^{2} \quad b_{2}=k_{p i} V_{d c} q_{2} T_{s}^{2}+p_{1} L_{f 1} T_{s} \\
& b_{1}=k_{p i} V_{d c} q_{1} T_{s}+p_{0} L_{f 1} \quad b_{0}=k_{p i} V_{d c} q_{0} \quad c=L_{f 2} .
\end{aligned}
$$


By equalizing (24) and (9) with $m=5$, i.e., $c=E, a_{i}=A_{i}$ $(i \in[0,5])$, and $b_{j}=B_{j}(j \in[0,5])$, the circuit and controller parameters can be identified as

$$
\begin{aligned}
L_{f 2}^{i d e n} & =E \quad k_{p i}^{i d e n}=\frac{B_{0}}{A_{0} V_{d c}} \quad C_{f}^{i d e n}=\frac{A_{5}}{B_{4}} \\
T_{s}^{i d e n} & =\frac{16 k_{p i}^{i d e n} V_{d c}\left(\frac{A_{1}}{B_{0}}-C_{f}^{i d e n}\right)}{9} \\
L_{f 1}^{i d e n} & =\frac{B_{1}}{A_{0}}+\frac{15 k_{p i}^{i d e n} V_{d c} T_{s}^{i d e n}}{16} .
\end{aligned}
$$

On the other hand, by substituting (23) into (8), $Z_{C C C}$ can be represented as

$Z_{C C C}=\frac{b_{5}^{\prime} s^{5}+b_{4}^{\prime} s^{4}+b_{3}^{\prime} s^{3}+b_{2}^{\prime} s^{2}+b_{1}^{\prime} s+b_{0}^{\prime}}{a_{6}^{\prime} s^{6}+a_{5}^{\prime} s^{5}+a_{4}^{\prime} s^{4}+a_{3}^{\prime} s^{3}+a_{2}^{\prime} s^{2}+a_{1}^{\prime} s+a_{0}^{\prime}}+c^{\prime} s$,

where

$$
\begin{aligned}
& a_{6}^{\prime}=p_{4}^{\prime} L_{f 1} C_{f} T_{s}^{4} \quad a_{5}^{\prime}=\left(k_{p i} V_{d c} q_{4}^{\prime} T_{s}^{4}+p_{3}^{\prime} L_{f 1} T_{s}^{3}\right) C_{f} \\
& a_{4}^{\prime}=p_{4}^{\prime} T_{s}^{4}+k_{p i} V_{d c} q_{3}^{\prime} C_{f} T_{s}^{3}+p_{2}^{\prime} L_{f 1} C_{f} T_{s}^{2} \\
& a_{3}^{\prime}=p_{3}^{\prime} T_{s}^{3}+k_{p i} V_{d c} q_{2}^{\prime} C_{f} T_{s}^{2}+p_{1}^{\prime} L_{f 1} C_{f} T_{s} \\
& a_{2}^{\prime}=p_{2}^{\prime} T_{s}^{2}+k_{p i} V_{d c} q_{1}^{\prime} C_{f} T_{s}+p_{0}^{\prime} L_{f 1} C_{f} \\
& a_{1}^{\prime}=p_{1}^{\prime} T_{s}+k_{p i} V_{d c} q_{0}^{\prime} C_{f} \quad a_{0}^{\prime}=p_{0}^{\prime}
\end{aligned}
$$

and

$$
\begin{aligned}
& b_{5}^{\prime}=p_{4}^{\prime} L_{f 1} T_{s}^{4} \quad b_{4}^{\prime}=\left(k_{p i} V_{d c} q_{4}^{\prime} T_{s}^{4}+p_{3}^{\prime} L_{f 1} T_{s}^{3}\right) \\
& b_{3}^{\prime}=k_{p i} V_{d c} q_{3}^{\prime} T_{s}^{3}+p_{2}^{\prime} L_{f 1} T_{s}^{2} \quad b_{2}^{\prime}=k_{p i} V_{d c} q_{2}^{\prime} T_{s}^{2}+p_{1}^{\prime} L_{f 1} T_{s} \\
& b_{1}^{\prime}=k_{p i} V_{d c} q_{1}^{\prime} T_{s}+p_{0}^{\prime} L_{f 1} \quad b_{0}^{\prime}=k_{p i} V_{d c} q_{0}^{\prime} \quad c^{\prime}=L_{f 2} .
\end{aligned}
$$

By equalizing (28) and (9) with $m=5$, i.e., $c^{\prime}=E, a_{i}^{\prime}=A_{i}$ $(i \in[0,5])$, and $b_{j}^{\prime}=B_{j}(j \in[0,5])$, the circuit and controller parameters can be identified as

$$
\begin{aligned}
L_{f 2}^{i d e n} & =E \quad k_{p i}^{i d e n}=\frac{B_{0}}{A_{0} V_{d c}} \quad C_{f}^{i d e n}=\frac{A_{5}}{B_{4}} \\
T_{s}^{i d e n} & =\frac{4 k_{p i}^{i d e n} V_{d c}\left(\frac{A_{1}}{B_{0}}-C_{f}^{i d e n}\right)}{3} \\
L_{f 1}^{i d e n} & =\frac{B_{1}}{A_{0}}+\frac{3 k_{p i}^{i d e n} V_{d c} T_{s}^{i d e n}}{4} .
\end{aligned}
$$

It can be seen that $T_{s}^{i d e n}$ and $L_{f 1}^{i d e n}$ are different in (27) and (31), even (24) and (28) are in the same polynomial transfer function form. Compared to (23), the Pade approximation (18) is able to obtain more accurate identification results, which will be shown in Section IV-B.

2) Further Identification of PLL Controller Parameters: Based on (2) and (12), the four components of $\mathbf{Z}_{\mathrm{GCC}}$ can be calculated as

$$
\begin{aligned}
& Z_{G C C d d}=Z_{G C C d d}^{s i m p}+\frac{G_{G C C d q}^{P L L} Z_{G C C q d}^{s i m p}}{1-G_{G C C q q}^{P L L}} \\
& Z_{G C C d q}=Z_{G C C d q}^{s i m p}+\frac{G_{G C C d q}^{P L L} Z_{G C C q q}^{s i m p}}{1-G_{G C C q q}^{P L L}} \\
& Z_{G C C q d}=\frac{Z_{G C C q d}^{s i m p}}{1-G_{G C C q q}^{P L L}} \quad Z_{G C C q q}=\frac{Z_{G C C q q}^{s i m p}}{1-G_{G C C q q}^{P L L}} .
\end{aligned}
$$

In the frequency range above PLL bandwidth, $G_{G C C d q}^{P L L}$ and $G_{G C C q q}^{P L L}$ can be regarded as zero, since $G_{P L L}$ is close to zero. Therefore, $\mathbf{Z}_{\mathrm{GCC}} \approx \mathbf{Z}_{\mathrm{GCC}}^{\text {simp }}$ in the high-frequency range. On the other hand, since $\mathbf{Z}_{\mathbf{G C C}}^{\text {simp }}$ is diagonally dominant (i.e., $Z_{G C C d d}^{s i m p} \gg Z_{G C C q d}^{s i m p}$ and $\left.Z_{G C C q q}^{s i m p} \gg Z_{G C C d q}^{s i m p}\right), Z_{G C C d d} \approx$ $Z_{G C C d d}^{s i m p}, Z_{G C C d q} \neq Z_{G C C d q}^{s i m p}, Z_{G C C q d} \neq Z_{G C C q d}^{s i m p}$, and $Z_{G C C q q} \neq Z_{G C C q q}^{s i m p}$ in low-frequency range.

$Z_{G C C}$ can be calculated based on (5) using the identified parameters of current controller, $L C L$ filter, and digital sampling time, which is denoted as $Z_{G C C}^{i d e n}$. According to (13) and (32), $G_{P L L}$ can be identified as

$$
G_{P L L}^{i d e n}=\frac{Z_{G C C q q}^{m e a}-Z_{G C C}^{i d e n}}{Z_{G C C q q}^{m e a}\left(V_{c, d}^{s m e a}+I_{g, d}^{s m e a} G_{c i}^{i d e n}\right) G_{d e l}^{i d e n} V_{d c}} .
$$

On its basis, PLL controller parameters can further be identified. PLL controller parameters of the VSC under CCC mode can be identified in a similar way.

In addition to the VSCs under GCC and CCC modes studied in this article, the VSCs can be controlled by various feedback strategies (e.g., capacitor-current proportional feedback, capacitor-voltage derivative feedback, and PCC-voltage feedforward) and outer loop control strategies (e.g., dc-link voltage control and power control) in practice. In [22], the identification algorithm in this article is modified to cope with GCC mode with capacitor-current proportional feedback. In [43], the output impedance model of the VSC under capacitorvoltage derivative feedback is proved to be the same as that under capacitor-current proportional feedback, which results in the same parameters identification algorithm. Modification of the identification algorithm to cope with PCC-voltage feedforward strategy should be further investigated. In this article, contributions of current control loop and PLL on the IFRs are identified by (16) to facilitate the aforementioned stepby-step parameters identification. This impedance division concept is further developed in [44] to identify the impedance contributions of PLL and outer power control loop, and in [45] to identify the impedance contributions of current control loop, PLL, dc-link voltage control loop, and PCC-voltage control loop. Based on the impedance division results in [44], [45], the parameters of various control loops can further be identified in a similar way as explained in this article.

In addition to the aforementioned various proportionalintegral-based feedback/outer control loops, the VSCs can also be under other advanced control strategies, e.g., the model predictive control which can include nonlinearities and constraints easily [46], [47]. An optimization algorithm is defined to minimize the cost function whose input is the output of the predictive model. Extension of the parameters identification concept in this article for the model predictive control can be a future work.

In some worse cases, not only the circuit and controller parameters but also the internal control structure is not provided by the vendors due to the industrial secrecy and intellectual property. Therefore, the VSC becomes a black box, and identification of internal parameters becomes impossible. However, the IFRs of the VSC can be fitted as a state-space model using the VF algorithm, whose state variables are virtual and do not have any physical meanings. The relevant work has been reported in [5], [6], [34], [35]. Although the virtual state- 
TABLE I

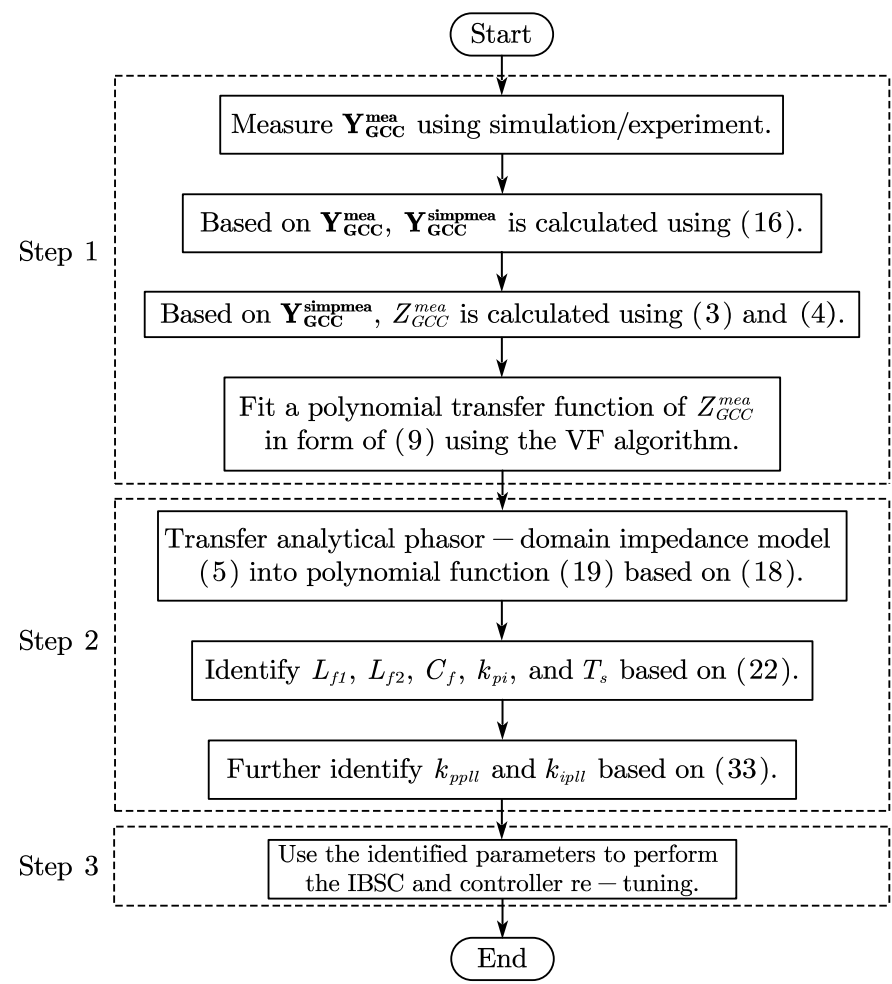

Fig. 2. Flowchart of the proposed parameters identification method of the VSCs under GCC mode.

space model can still be fitted from the terminal IFRs when the internal control structure is known, this article aims to explore the possibility to further identify the internal parameters based on both the IFRs and the VF algorithm.

\section{Implementation Procedure of the Proposed Parameters Identification Method}

Fig. 2 shows the implementation procedure of the proposed parameters identification method of the grid-connected VSCs, which consists of three main steps. In step $1, \mathbf{Y}_{\mathbf{G C C}}^{\mathbf{m e a}}$ is obtained using the frequency scanning method, from which $\mathbf{Y}_{\mathbf{G C C}}^{\text {simpmea }}$ is extracted using (16). Then, the corresponding phasor-domain IFRs $Z_{G C C}^{m e a}$ can be obtained using (3) and (4), which can be fitted as a polynomial function in form of (9) using the VF algorithm.

In step 2, the circuit and controller parameters of the VSC are identified from the fitted polynomial function. Taking GCC mode as an example, phasor-domain impedance model (5) is first reformulated as a polynomial function (19) based on the Pade approximation (18). Then, $L C L$ filter parameters (i.e., $L_{f 1}, L_{f 2}$, and $C_{f}$ ), proportional coefficient of the current controller (i.e., $k_{p i}$ ), and digital sampling time (i.e., $T_{s}$ ), are identified based on (22). On its basis, PLL controller parameters are further identified using (33). The circuit and controller parameters of the VSC under CCC mode can be identified in a similar way.

In step 3, the identified circuit and controller parameters are used in the IBSC and further controller re-tuning. For example, if instability phenomena occur when the VSC is connected to the weak grid, as shown in Fig. 1(a), the magnitude interaction
PARAMETERS OF THE TWO VSCS UNDER STUDY

\begin{tabular}{cccc}
\hline \hline Symbol & Description & GCC Mode & CCC Mode \\
\hline$V_{d c}$ & DC-link voltage & $400 \mathrm{~V}$ & $400 \mathrm{~V}$ \\
$\omega_{1}$ & Fundamental angular frequency & $314 \mathrm{rad} / \mathrm{s}$ & $314 \mathrm{rad} / \mathrm{s}$ \\
$L_{f 1}$ & Inverter-side filter inductance & $4 \mathrm{mH}$ & $3 \mathrm{mH}$ \\
$L_{f 2}$ & Grid-side filter inductance & $1.6 \mathrm{mH}$ & $2 \mathrm{mH}$ \\
$C_{f}$ & Filter capacitance & $5 \mu \mathrm{F}$ & $10 \mu \mathrm{F}$ \\
$f_{s w}$ & Switching frequency & $10 \mathrm{kHz}$ & $10 \mathrm{kHz}$ \\
$f_{s}$ & Sampling frequency & $10 \mathrm{kHz}$ & $10 \mathrm{kHz}$ \\
$V_{g}$ & Grid voltage (phase-to-phase magnitude) & $380 \mathrm{~V}$ & $380 \mathrm{~V}$ \\
$k_{p i}$ & Proportional gain of current controller & $0.0375 \Omega$ & $0.0325 \Omega$ \\
$k_{i i}$ & Integrator gain of current controller & $3.1212 \Omega / s$ & $4.8750 \Omega / s$ \\
$k_{p p l l}$ & Proportional gain of PLL & $5 \mathrm{rad} /\left(\mathrm{Vss}^{2}\right.$ & $10 \mathrm{rad} /(\mathrm{Vs})$ \\
$k_{i p l l}$ & Integrator gain of PLL & $6000 \mathrm{rad} /\left(\mathrm{Vs}^{2}\right)$ & $\left.4000 \mathrm{rad} /(\mathrm{Vs})^{2}\right)$ \\
$i_{g d}^{r e f}$ & $d$-axis current reference & $20 \mathrm{~A}$ & $20 \mathrm{~A}$ \\
$i_{g q}^{r e f}$ & $q$-axis current reference & $0 \mathrm{~A}$ & $0 \mathrm{~A}$ \\
\hline \hline
\end{tabular}

points of the measured $d q$-domain IFRs of both VSC and weak grid, i.e., $\mathbf{Z}_{\mathbf{G C C}}^{\text {mea }}$ and $\mathbf{Z}_{\mathrm{g}}^{\text {mea }}$, are identified. The parameters of current controller and PLL controller can then be re-tuned to mitigate the instability phenomena, which is able to help the vendors to re-design the control system to improve the stability of the VSC-grid system.

\section{THEORETICAL VERIFICATION}

In this section, the effectiveness of the proposed parameters identification method is theoretically validated. On its basis, influence of measurement noise on parameters identification accuracy and corresponding countermeasure to mitigate the adverse influence are discussed.

\section{A. Theoretical Verification of the Proposed Parameters Iden- tification Method}

The circuit and controller parameters of the VSCs under GCC and CCC modes are shown in Table I. $\mathbf{Z}_{\mathbf{G C C}}$ and $\mathbf{Z}_{\mathbf{G C C}}^{\text {simp }}$ are calculated based on (1) and (2), respectively, of which the Bode diagrams are plotted in Fig. 3(a). It can be seen that $\mathbf{Z}_{\mathbf{G C C}} \approx \mathbf{Z}_{\mathbf{G C C}}^{\text {simp }}$ in high-frequency range. In addition, $Z_{G C C d q}, Z_{G C C q d}$, and $Z_{G C C q q}$ are significantly affected by PLL dynamics in low-frequency range, whereas $Z_{G C C d d}$ is slightly influenced. The correctness of the theoretical analysis results in Section III-B2 is thus validated.

82 frequency points of $\mathbf{Z}_{\mathbf{G C C}}$ logarithmically distributed between $1 \mathrm{~Hz}$ and $5 \mathrm{kHz}$, i.e., $\mathbf{Z}_{\mathbf{G C C}}^{\text {theo }}$ in Fig. 3(a), are sampled to theoretically validate the effectiveness of the proposed parameters identification method. According to step 1 in Fig. 2 , the corresponding theoretical phasor-domain IFRs $Z_{G C C}^{\text {theo }}$ can be calculated from $\mathbf{Z}_{\mathbf{G C C}}^{\text {theo }}$, of which the Bode diagram is plotted in Fig. 3(b). Polynomial transfer functions in the form of (9) with orders 1st, 2nd, 3rd, and 5th are generated by applying the VF algorithm on the 82 frequency points, of which the Bode diagrams are plotted in Fig. 3(b). The fitting errors using different orders are calculated by (10) and shown in the second row of Table II, which indicates that fitting accuracy is generally increased as the fitting order increases. The 5th order is selected, since it achieves the trade-off between accuracy and complexity. The coefficients of the fitted 5th-order polynomial function are listed in the second column of Table III, based on which $L_{f 2}, k_{p i}, C_{f}$, 

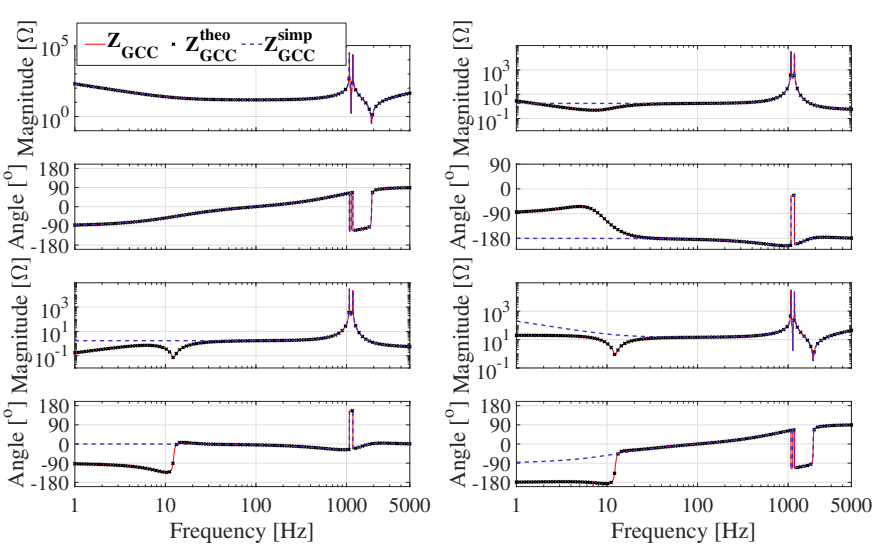

(a)

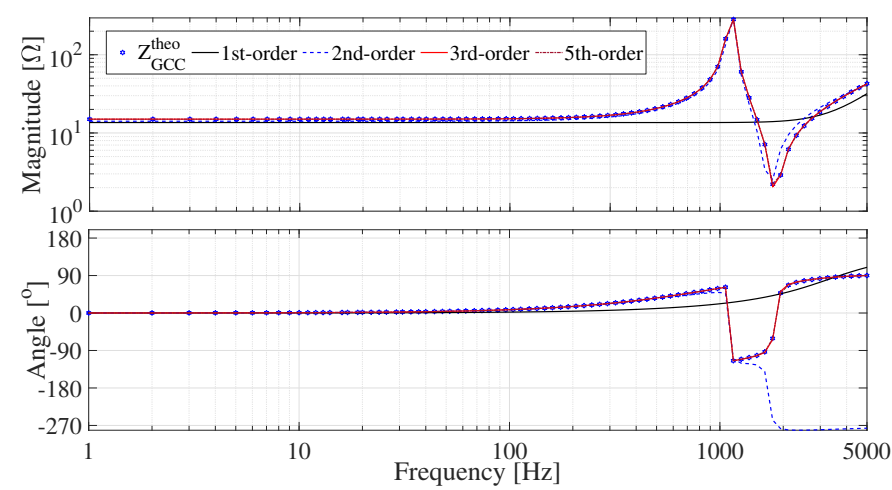

(b)

Fig. 3. Theoretical verification of the proposed parameters identification method for GCC mode. (a) Bode diagrams of the $d q$-domain IFRs. (b) Fitting results of $Z_{G C C}^{\text {theo }}$ with different orders.

TABLE II

FitTING ERRORS OF THE TwO CONVERTERS IN TABLE I WITH DIFFERENT ORDERS

\begin{tabular}{ccccccc}
\hline \hline Mode & 1st order & 2nd order & 3rd order & 5th order & 7th order & 9th order \\
\hline GCC & 39.0509 & 6.3220 & 0.1405 & $5.3127 \times 10^{-5}$ & 0.00289 & $3.7863 \times 10^{-5}$ \\
CCC & 6.1678 & 3.7238 & $2.8129 \times 10^{-4}$ & $2.9681 \times 10^{-8}$ & $1.1460 \times 10^{-7}$ & $1.1870 \times 10^{-11}$ \\
\hline \hline
\end{tabular}

$T_{s}$, and $L_{f 1}$ are calculated from (22). PLL parameters can further be identified based on (33). The identification errors of these parameters are also calculated in Table III. It can be seen that the identified circuit and controller parameters highly agree with the actual values in Table I. In addition, identification accuracy of $L C L$ filter parameters based on the proposed method is higher than that proposed in [14], where the identification errors of $L_{f 1}, L_{f 2}$, and $C_{f}$ are $8 \%, 2 \%$, and $12 \%$, respectively. It is worthwhile noting that different from experimental verification, the actual parameter values are exactly known in the theoretical verification, which enables better analysis of parameters identification accuracy.

Similarly, the $d q$-domain impedance models of the VSC under CCC mode with considering PLL $\mathbf{Z}_{\mathbf{C C C}}$ and without considering PLL $\mathbf{Z}_{\mathbf{C C C}}^{\text {simp }}$ are calculated based on (6) and (7), respectively, of which the Bode diagrams are plotted in Fig. 4(a). Similar with Fig. 3(a), it can be seen that, in lowfrequency range, $Z_{C C C d q}, Z_{C C C q d}$, and $Z_{C C C q q}$ are significantly affected by PLL dynamics, whereas $Z_{C C C d d}$ is slightly influenced. The correctness of the theoretical analysis results
TABLE III

COEFFicients OF THE FitTEd 5TH-ORder POLYNOMIAL TRANSFER FUNCTIONS AND CORRESPONDING IDENTIFIED PARAMETERS

\begin{tabular}{llll}
\hline \hline & Theo. GCC & Theo. CCC & Mea. GCC \\
\hline$A_{5}$ & 1 & 1 & 1 \\
$A_{4}$ & $1.2908 \mathrm{e}+05$ & $4.2246 \mathrm{e}+04$ & $1.3233 \mathrm{e}+05$ \\
$A_{3}$ & $6.6447 \mathrm{e}+09$ & $3.1850 \mathrm{e}+09$ & $6.3287 \mathrm{e}+09$ \\
$A_{2}$ & $1.3508 \mathrm{e}+14$ & $2.7315 \mathrm{e}+13$ & $1.4522 \mathrm{e}+14$ \\
$A_{1}$ & $3.2974 \mathrm{e}+17$ & $2.6342 \mathrm{e}+17$ & $4.2349 \mathrm{e}+17$ \\
$A_{0}$ & $6.4315 \mathrm{e}+21$ & $1.3946 \mathrm{e}+21$ & $6.7525 \mathrm{e}+21$ \\
$B_{5}$ & -5.1425 & $3.7252 \mathrm{e}-04$ & -0.0373 \\
$B_{4}$ & $3.0641 \mathrm{e}+05$ & $1.0006 \mathrm{e}+05$ & $5.2919 \mathrm{e}+05$ \\
$B_{3}$ & $1.0916 \mathrm{e}+10$ & $4.2147 \mathrm{e}+09$ & $3.0293 \mathrm{e}+10$ \\
$B_{2}$ & $1.7531 \mathrm{e}+15$ & $3.1614 \mathrm{e}+14$ & $3.8291 \mathrm{e}+15$ \\
$B_{1}$ & $1.6082 \mathrm{e}+19$ & $2.5319 \mathrm{e}+18$ & $1.4834 \mathrm{e}+19$ \\
$B_{0}$ & $9.6472 \mathrm{e}+22$ & $1.8130 \mathrm{e}+22$ & $1.1123 \mathrm{e}+23$ \\
$E$ & 0.0016 & 0.0020 & 0.0016 \\
\hline$L_{f 2}^{\text {iden }}[\mathrm{mH}]$ & $1.6(0 \%)$ & $2(0 \%)$ & $1.6(0 \%)$ \\
$k_{p i}^{\text {iden }}[\Omega]$ & $0.0375(0 \%)$ & $0.0325(0 \%)$ & $0.0412(9.87 \%)$ \\
$C_{f}^{\text {iden }}[\mu \mathrm{F}]$ & $5.29(5.80 \%)$ & $9.99(0.10 \%)$ & $5.13(2.60 \%)$ \\
$T_{s}^{\text {iden }}[\mu \mathrm{s}]$ & $91.15(8.85 \%)$ & $105(5.00 \%)$ & $111.50(11.50 \%)$ \\
$L_{f 1}^{i d e n}[\mathrm{mH}]$ & $3.8(5.00 \%)$ & $3.1(3.33 \%)$ & $3.9(2.50 \%)$ \\
$k_{\text {flen }}^{\text {iden }}[\mathrm{rad} /(\mathrm{Vs})]$ & $4.923(1.54 \%)$ & $9.738(2.62 \%)$ & $4.839(3.22 \%)$ \\
$k_{i p l l}^{\text {iden }}\left[\mathrm{rad} /\left(\mathrm{Vs}{ }^{2}\right)\right]$ & $6125(2.08 \%)$ & $4235(5.88 \%)$ & $5706(4.90 \%)$ \\
\hline \hline
\end{tabular}

in Section III-B2 is thus again validated. Fitting results of the 82-frequency-point-based phasor-domain IFRs using different orders are plotted in Fig. 4(b). The fitting errors using different orders are calculated by (10) and shown in the third row of Table II, which indicates that the 5th-order transfer function achieves the trade-off between accuracy and complexity. The identified circuit and controller parameters are listed in the third column of Table III, which highly agree with the actual values in Table I. On the other hand, the internal parameters identified by (31) are $L_{f 2}^{i d e n}=2 \mathrm{mH}(0 \%), k_{p i}^{i d e n}=0.0325 \Omega$ (0\%), $C_{f}^{\text {iden }}=9.99 \mu \mathrm{F}(0.10 \%), T_{s}^{i d e n}=78.75 \mu \mathrm{s}(21.25 \%)$, and $L_{f 1}^{i d e n}=2.58 \mathrm{mH}(14.00 \%)$. It can be seen that the identification accuracy using (31) is poorer than that using (27).

The $d q$-domain impedance characteristics in the highfrequency range are dominated by the current control loop, as explained in (32). Therefore, parameters of the current control loop can theoretically be identified from only the high-frequency $d q$-domain impedance data. However, PLL bandwidth calculation is impossible for the gray-box VSCs, which indicates that identification of the aforementioned highfrequency range is also impossible. To solve this gray-box issue, the current control loop-related $d q$-domain impedance data is extracted from terminal impedance data using (16), which is one main contribution of this article. On its basis, phasor-domain impedance data is calculated using (3) and (4). The aforementioned impedance transformation and application of the VF algorithm on the phasor-domain impedance data are illustrated in Figs. 3 and 4, which show that instead of using only the high-frequency $d q$-domain impedance data, the whole frequency range of the phasor-domain impedance data can be used, which thus does not require the identification of aforementioned high-frequency range and could provide more frequency points for parameters identification. 

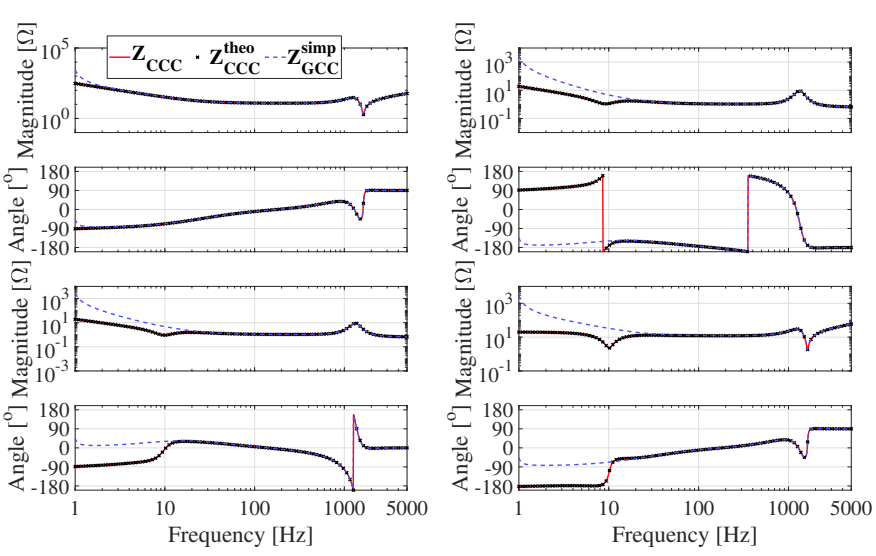

(a)

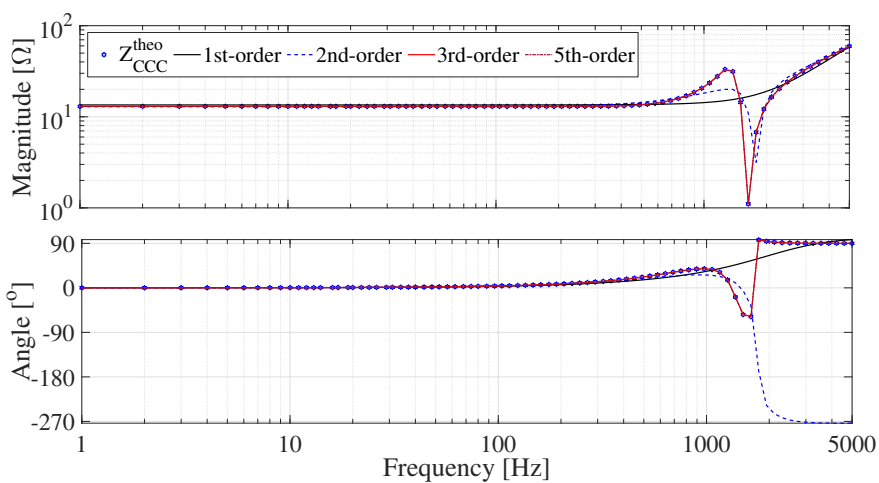

(b)

Fig. 4. Theoretical verification of the proposed parameters identification method for CCC mode. (a) Bode diagrams of the $d q$-domain IFRs. (b) Fitting results of $Z_{C C C}^{\text {theo }}$ with different orders.

\section{B. Influence of Measurement Noise on Parameters Identifica- tion Accuracy}

To quantitatively analyze the influence of measurement noise on parameters identification accuracy, 82 twodimensional random variables under normal distribution with mean value 0 and different standard deviations $\sigma$ from 0 to 1.6 are designed and collected in $\mathbf{X}_{\mathbf{8 2}}=\left\{\mathbf{x}_{\mathbf{1}}, \mathbf{x}_{\mathbf{2}} \ldots, \mathbf{x}_{\mathbf{8 2}}\right\}$. The 82 random variables are then added to the aforementioned 82 analytical $d q$-domain IFRs of $\mathbf{Z}_{\mathbf{C C C}}$, which is denoted as $\mathbf{Z}_{\mathbf{C C C}}^{\mathbf{8 2}}$. The perturbed $82 d q$-domain IFRs $\mathbf{Z}_{\mathbf{C C C p}}^{\mathbf{8 2}}$ can be expressed as

$$
\mathbf{Z}_{\mathbf{C C C p}}^{\mathbf{2}}=\mathbf{Z}_{\mathbf{C C C}}^{\mathbf{8 2}} \times\left(1+\mathbf{X}_{\mathbf{8 2}} / 100\right),
$$

where $\mathbf{x}_{\mathbf{i}} \sim N\left(0, \sigma^{2}\right)(\mathbf{i}=1,2 \ldots, 82)$. Similar to Fig. 4(b), parameters are identified from the fitted 5th-order polynomial transfer functions of the perturbed phasor-domain IFRs, as shown in Table IV. It can be seen that the identification accuracy becomes poor when the measurement noise becomes large, which indicates that the fitted 5th-order transfer function cannot incorporate the measurement noise well.

A higher order (e.g., 10th order) can then be selected. To extract the circuit and controller parameters from the fitted 10th-order transfer function, the parameters extraction scheme in (27) should be modified. Similar with the parameters identification process for the fitted 5th-order transfer function in Section III-B, $l$ and $k$ in the Pade approximation (17) can
TABLE IV

IDENTIFIED PARAMETERS FROM THE FITTED 5TH-ORDER POLYNOMIAL Transfer Functions With DifFERENT MEASUREMENT NoISES

\begin{tabular}{llllll}
\hline \hline & \multicolumn{5}{c}{ CCC mode (5th-order) } \\
\cline { 2 - 6 } & $\sigma=0$ & $\sigma=0.4$ & $\sigma=0.8$ & $\sigma=1.2$ & $\sigma=1.6$ \\
\hline$A_{5}$ & 1 & 1 & 1 & 1 & 1 \\
$A_{4}$ & $4.1853 \mathrm{e}+04$ & $-2.9443 \mathrm{e}+04$ & $-3.0751 \mathrm{e}+03$ & $-2.4859 \mathrm{e}+04$ & $-1.3226 \mathrm{e}+04$ \\
$A_{3}$ & $3.1373 \mathrm{e}+09$ & $1.7661 \mathrm{e}+09$ & $2.3681 \mathrm{e}+09$ & $1.6249 \mathrm{e}+09$ & $2.0446 \mathrm{e}+09$ \\
$A_{2}$ & $2.6904 \mathrm{e}+13$ & $1.3883 \mathrm{e}+13$ & $2.0304 \mathrm{e}+13$ & $1.3817 \mathrm{e}+13$ & $1.8096 \mathrm{e}+13$ \\
$A_{1}$ & $2.5933 \mathrm{e}+17$ & $1.5631 \mathrm{e}+17$ & $2.0386 \mathrm{e}+17$ & $1.4456 \mathrm{e}+17$ & $1.7909 \mathrm{e}+17$ \\
$A_{0}$ & $1.3726 \mathrm{e}+21$ & $9.6834 \mathrm{e}+20$ & $1.2310 \mathrm{e}+21$ & $9.6726 \mathrm{e}+20$ & $1.1833 \mathrm{e}+21$ \\
$B_{5}$ & $3.4681 \mathrm{e}-04$ & 0.0147 & -0.1583 & -0.1117 & 0.2965 \\
$B_{4}$ & $1.0007 \mathrm{e}+05$ & $9.9386 \mathrm{e}+04$ & $9.9982 \mathrm{e}+04$ & $1.0330 \mathrm{e}+05$ & $1.0997 \mathrm{e}+05$ \\
$B_{3}$ & $4.1753 \mathrm{e}+09$ & $-3.0019 \mathrm{e}+09$ & $-8.0411 \mathrm{e}+08$ & $-2.7571 \mathrm{e}+09$ & $-1.0421 \mathrm{e}+09$ \\
$B_{2}$ & $3.1137 \mathrm{e}+14$ & $1.7460 \mathrm{e}+14$ & $2.4070 \mathrm{e}+14$ & $1.6642 \mathrm{e}+14$ & $2.0941 \mathrm{e}+14$ \\
$B_{1}$ & $2.4928 \mathrm{e}+18$ & $1.3993 \mathrm{e}+18$ & $1.8709 \mathrm{e}+18$ & $1.2931 \mathrm{e}+18$ & $1.6518 \mathrm{e}+18$ \\
$B_{0}$ & $1.784 \mathrm{e}+22$ & $1.2601 \mathrm{e}+22$ & $1.6023 \mathrm{e}+22$ & $1.2554 \mathrm{e}+22$ & $1.5217 \mathrm{e}+22$ \\
$E$ & 0.0020 & 0.0020 & 0.0020 & 0.0020 & 0.0020 \\
\hline$L_{f 2}^{\text {iden }}[\mathrm{mH}]$ & $2(0 \%)$ & $2(0 \%)$ & $2(0 \%)$ & $2(0 \%)$ & $2(0 \%)$ \\
$k_{p i}^{\text {iden }}[\Omega]$ & $0.0325(0 \%)$ & $0.0325(0 \%)$ & $0.0326(0.31 \%)$ & $0.0325(0 \%)$ & $0.0322(0.92 \%)$ \\
$C_{f}^{\text {iden }}[\mu \mathrm{F}]$ & $9.99(0.10 \%)$ & $10.06(0.60 \%)$ & $10.00(0 \%)$ & $9.683 .20 \%$ & $9.09(9.10 \%)$ \\
$T_{s}^{\text {iden }}[\mu \mathrm{s}]$ & $104.92(4.92 \%)$ & $54.23(45.77 \%)$ & $63.03(36.97 \%)$ & $42.34(57.66 \%)$ & $61.25(38.75 \%)$ \\
$L_{f 1}^{\text {iden }}[\mathrm{mH}]$ & $3.08(2.67 \%)$ & $2.11(29.67 \%)$ & $2.29(23.67 \%)$ & $1.85(38.33 \%)$ & $2.13(29.00 \%)$ \\
\hline \hline
\end{tabular}

TABLE V

IDENTIFIED PARAMETERS FROM THE FITTED 10TH-ORDER POLYNOMIAL TRANSFER Functions WITH DifFERENT MEASUREMENT NoISES

\begin{tabular}{|c|c|c|c|c|c|}
\hline & \multicolumn{5}{|c|}{ CCC mode (10th-order) } \\
\hline & $\sigma=0$ & $\sigma=0.4$ & $\sigma=0.8$ & $\sigma=1.2$ & $\sigma=1.6$ \\
\hline$A_{10}$ & 1 & 1 & 1 & 1 & 1 \\
\hline$A_{9}$ & $2.7278 \mathrm{e}+05$ & $4.0656 \mathrm{e}+04$ & $4.9734 \mathrm{e}+04$ & $5.9781 \mathrm{e}+04$ & $3.8977 \mathrm{e}+04$ \\
\hline$A_{8}$ & $5.7949 \mathrm{e}+10$ & $7.6188 \mathrm{e}+09$ & $7.8443 \mathrm{e}+09$ & $7.9267 \mathrm{e}+09$ & $7.6942 \mathrm{e}+09$ \\
\hline$A_{7}$ & $8.2491 \mathrm{e}+15$ & $2.8397 \mathrm{e}+14$ & $3.3077 \mathrm{e}+14$ & $3.7832 \mathrm{e}+14$ & $2.6013 \mathrm{e}+14$ \\
\hline$A_{6}$ & $7.5109 \mathrm{e}+20$ & $1.8244 \mathrm{e}+19$ & $1.9052 \mathrm{e}+19$ & $1.9376 \mathrm{e}+19$ & $1.8013 \mathrm{e}+19$ \\
\hline$A_{5}$ & $5.9001 \mathrm{e}+25$ & $5.9944 \mathrm{e}+23$ & $6.8233 e+23$ & $7.4068 \mathrm{e}+23$ & $5.2649 \mathrm{e}+23$ \\
\hline$A_{4}$ & $2.3553 \mathrm{e}+30$ & $1.5304 \mathrm{e}+28$ & $1.6107 \mathrm{e}+28$ & $1.6426 \mathrm{e}+28$ & $1.3952 \mathrm{e}+28$ \\
\hline$A_{3}$ & $8.9435 \mathrm{e}+34$ & $3.9382 \mathrm{e}+32$ & $4.4102 \mathrm{e}+32$ & $4.5547 \mathrm{e}+32$ & $3.2603 \mathrm{e}+32$ \\
\hline$A_{2}$ & $7.7218 \mathrm{e}+38$ & $3.3804 \mathrm{e}+36$ & $3.7412 \mathrm{e}+36$ & $3.9325 \mathrm{e}+36$ & $2.5030 \mathrm{e}+36$ \\
\hline$A_{1}$ & $6.9555 \mathrm{e}+42$ & $2.8087 \mathrm{e}+40$ & $3.1684 \mathrm{e}+40$ & $3.2995 \mathrm{e}+40$ & $2.3560 \mathrm{e}+40$ \\
\hline$A_{0}$ & $3.4147 \mathrm{e}+46$ & $1.3439 \mathrm{e}+44$ & $1.5167 \mathrm{e}+44$ & $1.6172 \mathrm{e}+44$ & $7.6583 e+43$ \\
\hline$B_{10}$ & $2.5763 \mathrm{e}-05$ & -0.0115 & -0.4085 & 0.4974 & -0.4638 \\
\hline$B_{9}$ & $1.0001 \mathrm{e}+05$ & $9.9339 \mathrm{e}+04$ & $9.7115 \mathrm{e}+04$ & $1.0474 \mathrm{e}+05$ & $1.2420 \mathrm{e}+05$ \\
\hline$B_{8}$ & $2.7276 \mathrm{e}+10$ & $4.0083 \mathrm{e}+09$ & $2.3596 \mathrm{e}+09$ & $8.8876 \mathrm{e}+09$ & $2.3176 \mathrm{e}+08$ \\
\hline$B_{7}$ & $5.7921 \mathrm{e}+15$ & $7.5466 \mathrm{e}+14$ & $7.7857 e+14$ & $8.1010 \mathrm{e}+14$ & $9.3691 \mathrm{e}+14$ \\
\hline$B_{6}$ & $8.2396 \mathrm{e}+20$ & $2.8207 \mathrm{e}+19$ & $2.7615 \mathrm{e}+19$ & $4.2752 \mathrm{e}+19$ & $1.3652 \mathrm{e}+19$ \\
\hline$B_{5}$ & $7.4916 \mathrm{e}+25$ & $1.7904 \mathrm{e}+24$ & $1.8984 \mathrm{e}+24$ & $1.9427 \mathrm{e}+24$ & $2.1624 \mathrm{e}+24$ \\
\hline$B_{4}$ & $5.8734 \mathrm{e}+30$ & $5.9099 \mathrm{e}+28$ & $6.3555 \mathrm{e}+28$ & $7.5181 \mathrm{e}+28$ & $3.7243 \mathrm{e}+28$ \\
\hline$B_{3}$ & $2.3291 \mathrm{e}+35$ & $1.4613 \mathrm{e}+33$ & $1.5697 \mathrm{e}+33$ & $1.6012 \mathrm{e}+33$ & $1.6438 \mathrm{e}+33$ \\
\hline$B_{2}$ & $8.7607 e+39$ & $3.7602 \mathrm{e}+37$ & $4.1489 \mathrm{e}+37$ & $4.2911 \mathrm{e}+37$ & $2.4517 \mathrm{e}+37$ \\
\hline$B_{1}$ & $6.8568 \mathrm{e}+43$ & $2.8229 \mathrm{e}+41$ & $3.2095 \mathrm{e}+41$ & $3.4071 \mathrm{e}+41$ & $2.7167 e+41$ \\
\hline$B_{0}$ & $4.4391 \mathrm{e}+47$ & $1.7374 \mathrm{e}+45$ & $1.9532 \mathrm{e}+45$ & $2.0473 e+45$ & $9.0312 \mathrm{e}+44$ \\
\hline$E$ & 0.0020 & 0.0020 & 0.0020 & 0.0020 & 0.0020 \\
\hline$L_{f 2}^{i d e n}[\mathrm{mH}]$ & $2(0 \%)$ & $2(0 \%)$ & $2(0 \%)$ & $2(0 \%)$ & $2(0 \%)$ \\
\hline$k_{p i}^{i d e n}[\Omega]$ & $0.0325(0 \%)$ & $0.0323(0.62 \%)$ & $0.0322(0.92 \%)$ & $0.0317(2.46 \%)$ & $0.0295(9.23 \%)$ \\
\hline$C_{f}^{\text {iden }}[\mu \mathrm{F}]$ & $10.00(0 \%)$ & $10.07(0.70 \%)$ & $10.30(3.00 \%)$ & $9.55(4.50 \%)$ & $8.05(19.50 \%)$ \\
\hline$T_{s}^{\text {iden }}[\mu \mathrm{s}]$ & $98.26(1.74 \%)$ & $105.10(5.10 \%)$ & $101.69(1.69 \%)$ & $110.84(10.84 \%)$ & $283.55(183.55 \%)$ \\
\hline$L_{f 1}^{\text {iden }}[\mathrm{mH}]$ & $2.97(1.00 \%)$ & $3.12(4.00 \%)$ & $3.10(3.33 \%)$ & $3.16(5.33 \%)$ & $6.05(101.67 \%)$ \\
\hline
\end{tabular}

be chosen as either $l=m, k=m-2$ or $l=k=m-1$ for the $m$ th-order transfer function. It can be found that, in the case $m>10$, the identification accuracy is higher if $l=k=m-1$. $p_{0}, p_{1}, q_{0}$, and $q_{1}$ in (17) can then be calculated as

$$
\begin{aligned}
& p_{0}=q_{0}=(2 m-2) ! \\
& p_{1}=(m-1)(2 m-3) ! \\
& q_{1}=-(m-1)(2 m-3) !
\end{aligned}
$$

Then, the circuit and controller parameters can be identification as (The detailed derivation process is omitted here.)

$$
\begin{aligned}
L_{f 2}^{i d e n} & =E \quad k_{p i}^{i d e n}=\frac{B_{0}}{A_{0}} \quad C_{f}^{i d e n}=\frac{A_{m}}{B_{m-1}} \\
T_{s}^{i d e n} & =\frac{2 q_{0} k_{p i}^{i d e n}\left(\frac{A_{1}}{B_{0}}-C_{f}^{i d e n}\right)}{3 p_{1}}=\frac{4 k_{p i}^{i d e n}\left(\frac{A_{1}}{B_{0}}-C_{f}^{i d e n}\right)}{3} \\
L_{f 1}^{i d e n} & =\frac{B_{1}}{A_{0}}+\frac{3 k_{p i}^{i d e n} T_{s}^{i d e n}}{4} .
\end{aligned}
$$

The identified circuit and current controller parameters using (36) are listed in Table V. It can be seen from Tables IV and $\mathrm{V}$ that the fitted 10th-order transfer functions can identify the 
TABLE VI

IDENTIFIED PARAMETERS WITH MEASUREMENT NoISE $\sigma=1.6$ USING DIFFERENT ORDERS

\begin{tabular}{llllll}
\hline \hline & \multicolumn{5}{c}{ CCC mode } \\
\cline { 2 - 6 } & $m=12$ & $m=14$ & $m=16$ & $m=18$ & $m=20$ \\
\hline$A_{m}$ & 1 & 1 & 1 & 1 & 1 \\
$A_{1}$ & $4.4303 \mathrm{e}+49$ & $5.4718 \mathrm{e}+58$ & $4.3222 \mathrm{e}+67$ & $3.5690 \mathrm{e}+76$ & $2.5947 \mathrm{e}+85$ \\
$A_{0}$ & $2.1560 \mathrm{e}+53$ & $2.5508 \mathrm{e}+62$ & $1.9866 \mathrm{e}+71$ & $1.6053 \mathrm{e}+80$ & $1.1162 \mathrm{e}+89$ \\
$B_{m-1}$ & $1.0011 \mathrm{e}+05$ & $9.0716 \mathrm{e}+04$ & $9.1227 \mathrm{e}+04$ & $8.9605 \mathrm{e}+04$ & $8.6642 \mathrm{e}+04$ \\
$B_{1}$ & $4.4514 \mathrm{e}+50$ & $5.3701 \mathrm{e}+59$ & $4.2676 \mathrm{e}+68$ & $3.5466 \mathrm{e}+77$ & $2.6042 \mathrm{e}+86$ \\
$B_{0}$ & $2.7547 \mathrm{e}+54$ & $3.3034 \mathrm{e}+63$ & $2.5656 \mathrm{e}+72$ & $2.0736 \mathrm{e}+81$ & $1.4563 \mathrm{e}+90$ \\
$E$ & 0.0020 & 0.0020 & 0.0020 & 0.0020 & 0.0020 \\
\hline$L_{f 2}^{\text {iden }}[\mathrm{mH}]$ & $2(0 \%)$ & $2(0 \%)$ & $2(0 \%)$ & $2(0 \%)$ & $2(0 \%)$ \\
$k_{p i}^{\text {den }}[\Omega]$ & $0.0320(1.54 \%)$ & $0.0324(0.31 \%)$ & $0.0323(0.62 \%)$ & $0.0323(0.62 \%)$ & $0.0326(0.31 \%)$ \\
$C_{f}^{\text {iden }}[\mu \mathrm{F}]$ & $9.99(0.10 \%)$ & $11.02(10.20 \%)$ & $10.96(9.60 \%)$ & $11.16(11.60 \%)$ & $11.54(15.40 \%)$ \\
$T_{s}^{\text {iden }}[\mu \mathrm{s}]$ & $103.82(3.82 \%)$ & $95.73(4.27 \%)$ & $101.33(1.33 \%)$ & $104.25(4.25 \%)$ & $109.22(9.22 \%)$ \\
$L_{f 1}^{\text {iden }}[\mathrm{mH}]$ & $3.06(2.00 \%)$ & $3.04(1.33 \%)$ & $3.13(4.33 \%)$ & $3.23(7.67 \%)$ & $3.40(13.33 \%)$ \\
\hline \hline
\end{tabular}

parameters more accurately than the fitted 5th-order transfer functions when $\sigma=0.4,0.8$, and 1.2. To obtain a more accurate identification result for $\sigma=1.6$, higher orders can be used. The identified parameters when $m=12,14,16,18$, and 20 are listed in Table VI. It can be seen that these fitted higher-order transfer functions are able to identify parameters more accurately than the 10th-order transfer function.

Similarly, (22) can also be modified to identify the circuit and controller parameters from the fitted higher-order transfer functions for the VSCs under GCC mode, which is omitted in this article for simplicity.

\section{Simulation AND Experimental VERIFICATION}

In this section, the effectiveness of the proposed parameters identification method is verified by the OPAL-RT-based realtime simulation results and PHiL-based experimental results.

\section{A. Real-Time Simulation Verification Based on OPAL-RT Plat- form}

Real-time simulation verification based on OP5600 OPALRT digital simulator is performed to validate the effectiveness of the presented parameters identification method for controller parameters re-tuning to improve system stability. The OP5600 combines the power and reliability of Intel Xeon E5 processing cores with the high-performance latest generation Xilinx Virtex-6 FPGA (ML605) to address a wide range of rapid control prototyping applications with OPAL-RT's RTLAB or HYPERSIM software platforms. If the real-time simulator is used, the practical unpredictable influence factors (e.g., variation of $L C L$ parameters, parasitic resistance, effect of isolation transformer, and accuracy of sensors) in the real VSC can be avoided, and the capability of the VF algorithm itself can be the point of focus. Therefore, first both the circuit and control sub-systems are modeled in the OPAL-RT simulator. The code is then generated from the Matlab/Simulinkbased model and downloaded into the OP5600 hardware. The simulation model implemented in OPAL-RT software is run in the $\mathrm{CPU}$, while the D/A and A/D conversions are implemented in the FPGA. Both software and hardware platforms allow high-speed and real-time simulation. The real-time simulation results obtained by OPAL-RT platform are then post-processed in Matlab.

The real-time simulation verification may use the multi-rate simulation solver, which aims to reduce computational burden by adopting the most appropriate time steps, i.e., a small time step is selected for the sub-system with fast dynamics, whereas a large time step is selected for the sub-system with slow dynamics. For example, the circuit sub-system that requires high fidelity is implemented in a single CPU core, while the control sub-system that should use a larger time step is run in another CPU core. In this article, only one CPU core is used for simplicity. Specifically, the simulation time steps of both circuit and control sub-systems are $20 \mu \mathrm{s}$, and the average execution time of the computation in each step is $2.75 \mu \mathrm{s}$ which gives $13.76 \%$ of CPU usage.

1) Case 1: Fig. 1(a) shows the configuration of the studied system, where the gray-box VSC under GCC mode is connected to the utility grid. Fig. 5(a) shows the real-time simulation verification results of three-phase PCC voltages and grid currents when $R_{g}$ changes from $0.2 \Omega$ to $0.5 \Omega$, and $L_{g}$ changes from $0.2 \mathrm{mH}$ to $1 \mathrm{mH}$ at $1 \mathrm{~s}$. In addition, $R_{C_{g}}=0.1$ $\Omega$ and $C_{g}=10 \mu \mathrm{F}$. It can be seen that the system becomes unstable at $1 \mathrm{~s}$. The frequency spectrum of the grid current between $1 \mathrm{~s}$ and $2 \mathrm{~s}$ is shown in Fig. 5(b), which indicates that the system oscillates at $1364 \mathrm{~Hz}$. In order to identify the origins of the high-frequency oscillation phenomena, the Bode diagrams of the $d q$-domain IFRs of the VSC, the stable grid, and the unstable grid measured by the frequency scanning method are plotted as $\mathbf{Z}_{\mathbf{G C C}}^{\text {mea }}, \mathbf{Z}_{\mathbf{g} 1}^{\text {mea }}$, and $\mathbf{Z}_{\mathbf{g} 2}^{\text {mea }}$ in Fig. 6(a), respectively. Fig. 6(b) shows that magnitude interaction point of the VSC and the grid moves from point A $(1781 \mathrm{~Hz})$ to point $\mathrm{B}(1376 \mathrm{~Hz})$. The phase angle difference at point B is $74^{\circ}-\left(-107^{\circ}\right)=181^{\circ}>180^{\circ}$, which indicates that the system is unstable at $1376 \mathrm{~Hz}$. In addition, the Bode diagrams of the theoretical $d q$-domain IFRs of the VSC calculated by (1), the stable grid, and the unstable grid are plotted as $\mathbf{Z}_{\mathbf{G C C}}$, $\mathbf{Z}_{\mathrm{g} 1}$, and $\mathbf{Z}_{\mathrm{g} 2}$ in Fig. 6(a), respectively. It can be seen that the frequency scanning-obtained and the theoretically-derived $d q$ domain IFRs highly agree with each other, which shows the effectiveness of the measured $d q$-domain IFRs for IBSC. The minor difference between the identified instability frequency $1376 \mathrm{~Hz}$ in Fig. 6(b) and the real-time simulation-obtained instability frequency $1364 \mathrm{~Hz}$ in Fig. 5(b) results from the limited resolution of the step size of frequency scanning, which can be reduced by increasing the measurement frequency points. The current controller parameters should be re-tuned to mitigate the high-frequency instability phenomena.

According to step 1 and step 2 of the flowchart of the proposed parameters identification method in Fig. 2, circuit and controller parameters can be identified from $\mathbf{Z}_{\mathbf{G C C}}^{\mathrm{mea}}$, as shown in Table III. The Bode diagram of the measured $d q$ domain IFRs the VSC by decreasing $k_{p i}$ from identified value $0.0412 \Omega$ to re-tuned value $0.030 \Omega$ is shown as $\mathbf{Z}_{\mathrm{GCC}}^{\text {mearet } 1}$ in Fig. 7(a). Fig. 7(b) shows that the phase angle difference of $\mathbf{Z}_{\mathrm{GCC}}^{\text {meare } 1}$ and $\mathbf{Z}_{\mathbf{g} 2}^{\text {mea }}$ at magnitude interaction point $\mathrm{D}$ (1376 $\mathrm{Hz})$ is $74^{\circ}-\left(-99^{\circ}\right)=173^{\circ}<180^{\circ}$, which indicates that the system is stabilized.

The real-time simulation verification results of the threephase grid currents after current controller parameters retuning are shown after $2 \mathrm{~s}$ in Fig. 5(a). The frequency spectrum in Fig. 5(c) shows that the grid current has a decaying frequency component at $1821 \mathrm{~Hz}$ between $2 \mathrm{~s}$ and $3 \mathrm{~s}$. 


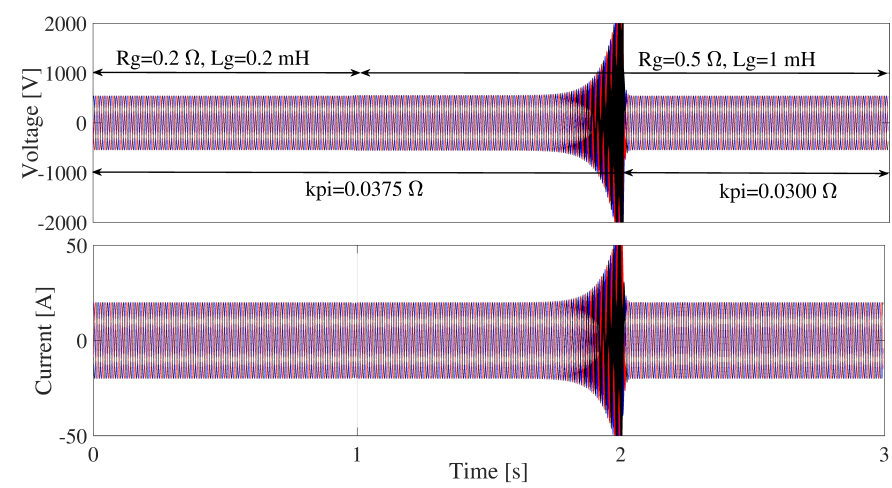

(a)

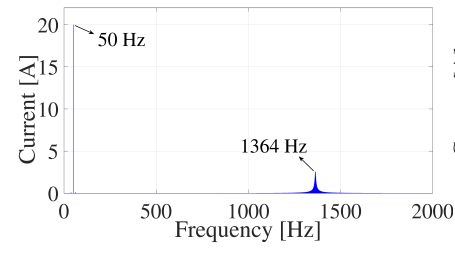

(b)

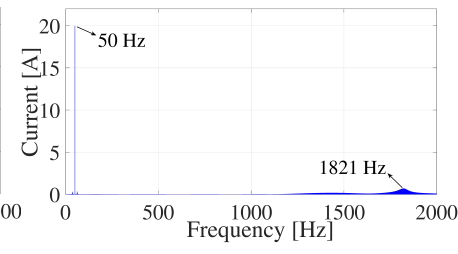

(c)
Fig. 5. Real-time simulation verification results for case 1 based on OPAL-RT platform. (a) Time-domain waveforms of three-phase PCC voltages and grid currents. (b) DFT of grid current between $1 \mathrm{~s}$ and $2 \mathrm{~s}$. (c) DFT of grid current between $2 \mathrm{~s}$ and $3 \mathrm{~s}$.

The real-time simulation verification results agree with the impedance-based stability analysis results in Fig. 6(a). The re-tuned current controller parameters can be delivered to the vendor for system parameters modification.

2) Case 2: Fig. 8(a) shows the real-time simulation verification results of three-phase PCC voltages and grid currents when $R_{g}$ changes from $0.2 \Omega$ to $0.7 \Omega$, and $L_{g}$ changes from $0.2 \mathrm{mH}$ to $6 \mathrm{mH}$ at $1.9 \mathrm{~s}$. In addition, $R_{C_{g}}=0.1 \Omega$ and $C_{g}=10 \mu \mathrm{F}$. It can be seen that the system becomes unstable at $1.9 \mathrm{~s}$. The frequency spectrum of the grid current between $1.9 \mathrm{~s}$ and $3.3 \mathrm{~s}$ is shown in Fig. 8(b), which indicate that the system oscillates at $38 \mathrm{~Hz}$ and $62 \mathrm{~Hz}$. To identify the origins of the low-frequency oscillation phenomena, the Bode diagrams of the $d q$-domain IFRs of the VSC, the stable grid condition, and the unstable grid condition measured by the frequency scanning method are plotted as $\mathbf{Z}_{\mathbf{G C C}}^{\text {mea }}, \mathbf{Z}_{\mathrm{g} 1}^{\text {mea }}$, and $\mathrm{Z}_{\mathrm{g} 3}^{\text {mea }}$ in Fig. 6(a), respectively. Fig. 6(c) shows that magnitude interaction point of the VSC and the grid moves from point $\mathrm{A}$ $(1781 \mathrm{~Hz})$ to point $\mathrm{C}(12 \mathrm{~Hz})$. The phase angle difference at point $\mathrm{C}$ is $33^{\circ}-\left(-150^{\circ}\right)=183^{\circ}>180^{\circ}$, which indicates that the system will be unstable at $62 \mathrm{~Hz}$ and $38 \mathrm{~Hz}$. PLL controller parameters should be re-tuned to mitigate the low-frequency instability phenomena.

Based on the identified parameters in Table III, the lowfrequency instability phenomena can be mitigated by decreasing PLL controller parameters. For example, the Bode diagram of the measured $d q$-domain IFRs of the VSC by decreasing $k_{p p l l}$ and $k_{i p l l}$ from identified values $4.839 \mathrm{rad} /(\mathrm{Vs})$ and 5706 $\mathrm{rad} /\left(\mathrm{Vs}^{2}\right)$ to re-tuned values $3 \mathrm{rad} /(\mathrm{Vs})$ and $2000 \mathrm{rad} /\left(\mathrm{Vs}^{2}\right)$ is shown as $\mathbf{Z}_{\mathrm{GCC}}^{\text {mearet2 }}$ in Fig. 7(a). Fig. 7(c) shows that the phase angle difference of $\mathbf{Z}_{\mathrm{GCC}}^{\text {meare } 2}$ and $\mathbf{Z}_{\mathrm{g} 3}^{\text {mea }}$ at magnitude interaction point $\mathrm{E}(7 \mathrm{~Hz})$ is $21^{\circ}-\left(-138^{\circ}\right)=159^{\circ}<180^{\circ}$,

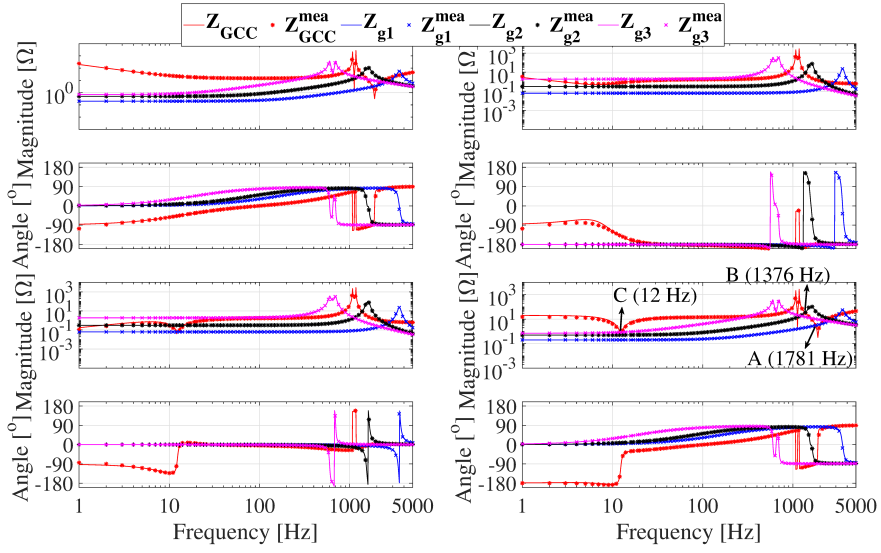

(a)
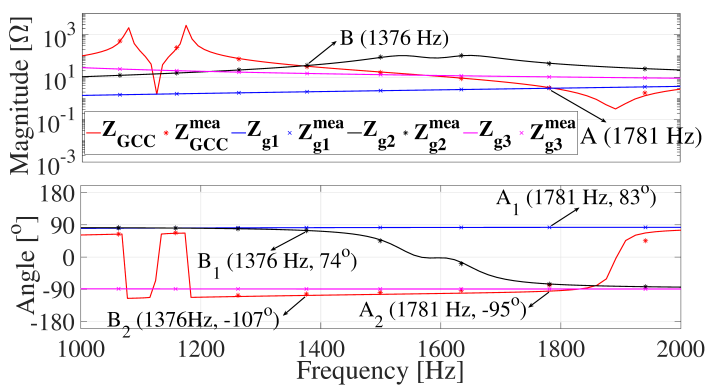

(b)

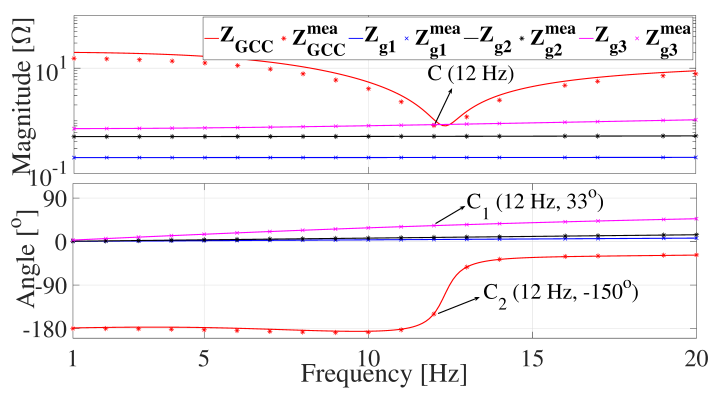

(c)

Fig. 6. Bode diagrams of the $d q$-domain IFRs of the VSC and grid. (a) Full view of the $d q$-domain IFRs. (b) Zoomed view of $q$-axis IFRs in highfrequency range. (c) Zoomed view of $q$-axis IFRs in low-frequency range.

which indicates that the system is stabilized.

The real-time simulation verification results of the threephase grid currents after current controller parameters retuning are shown after $3.3 \mathrm{~s}$ in Fig. 8(a). The frequency spectrum in Fig. 8(c) shows that the grid current has two decaying frequency components at $43 \mathrm{~Hz}$ and $57 \mathrm{~Hz}$ between $3.3 \mathrm{~s}$ and $10 \mathrm{~s}$. The real-time verification results agree with the impedance-based stability analysis results in Fig. 7(c).

In addition to the theoretical verification of the adaptive order-selection scheme for measurement noise mitigation in Tables IV, V, and VI, the similar verification can also be performed in simulation or experimental environment. For example, based on the frequency scanning strategy in [36], threephase grid current responses when PCC voltage is perturbed can further be manually perturbed by a random white noise using (34). This artificially-produced measurement noise of three-phase grid current responses can then bring in inaccuracy 


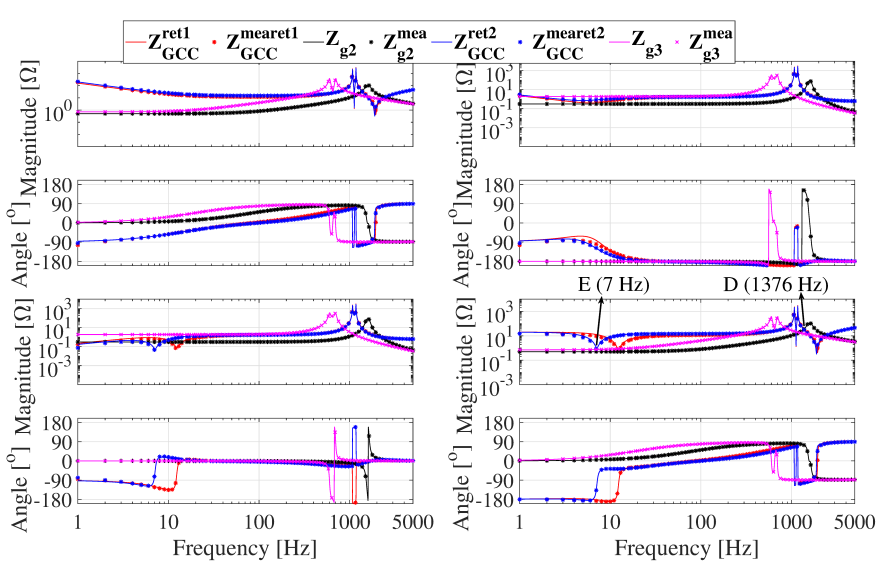

(a)

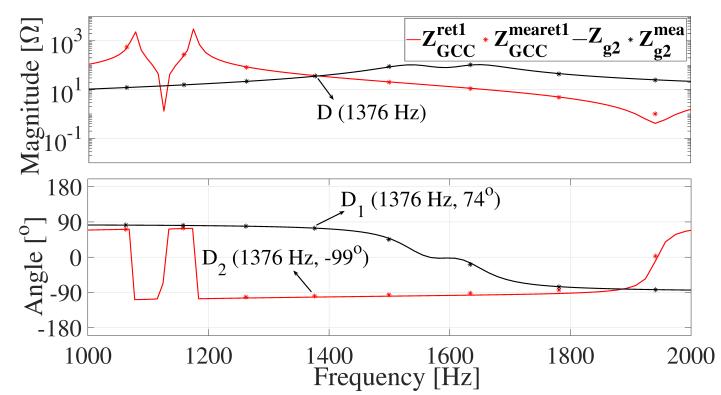

(b)

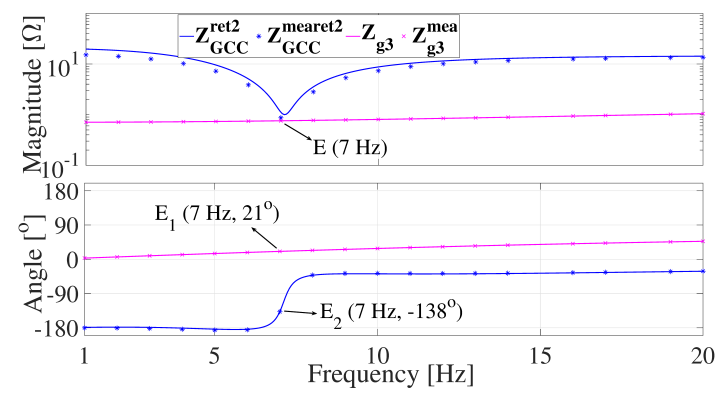

(c)

Fig. 7. Bode diagrams of the $d q$-domain IFRs of the VSC and grid by retuning current controller or PLL controller parameters. (a) Full view of the $d q$-domain IFRs. (b) Zoomed view of $q$-axis IFRs in high-frequency range. (c) Zoomed view of $q$-axis IFRs in low-frequency range.

of the $d q$-domain IFRs calculation, which makes the same effect as directly adding artificially-produced measurement noise to the $d q$-domain IFRs. However, the former scheme is less intuitive than the latter scheme. Since this article aims to theoretically show that the VF algorithm with adaptive orderselection can extract the circuit and controller parameters from the nonideal IFRs, the latter scheme is adopted. Furthermore, the IFRs measurement in step 1 of Fig. 2 and the parametric transfer function fitting in step 2 of Fig. 2 are implemented in MATLAB/Simulink environment in our article. Actually, Matlab is not strictly needed. For example, online impedance measurement of the grid and the VSC is investigated in [28], where real-time non-parametric IFRs are measured in OPALRT platform, and parametric polynomial impedance transfer function is generated in the LabVIEW platform.

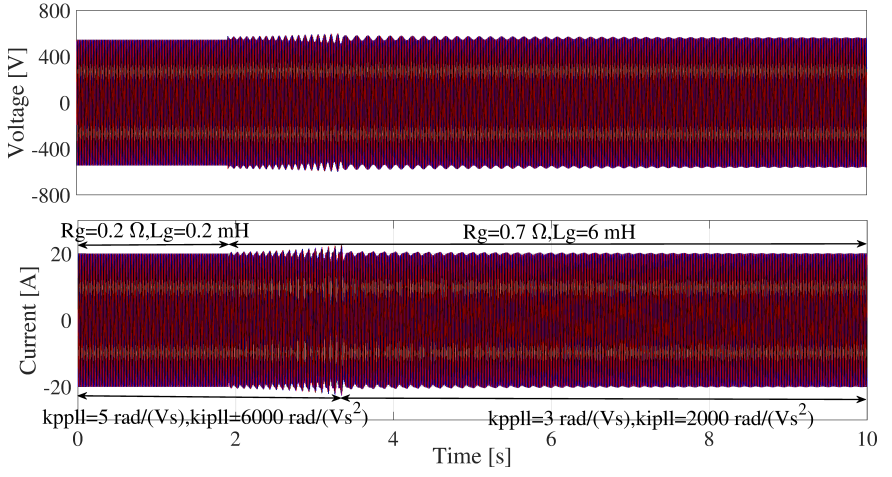

(a)

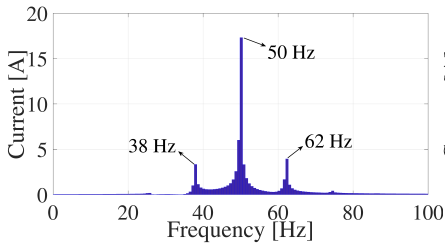

(b)

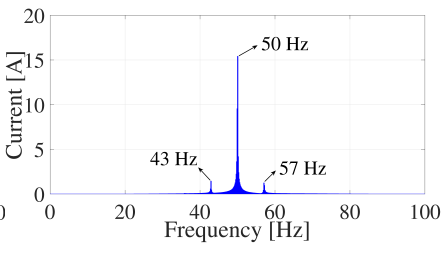

(c)
Fig. 8. Real-time simulation verification results for case 2 based on OPAL-RT platform. (a) Time-domain waveforms of three-phase PCC voltages and grid currents. (b) DFT of grid current between $1.9 \mathrm{~s}$ and $3.3 \mathrm{~s}$. (c) DFT of grid current between $3.3 \mathrm{~s}$ and $10 \mathrm{~s}$.

\section{B. Power-Hardware-in-the-Loop Experimental Validation}

1) Description of Laboratory Setup: Fig. 9 shows the picture and single-line diagram of the PHiL-based experimental setup in the Norwegian National Smart Grid Laboratory. The physical VSC is under CCC mode, and its rated power is 60 $\mathrm{kVA}$. Its circuit and controller parameters are as follows. $V_{d c}$ is $700 \mathrm{~V}$. $L_{f 1}, L_{f 2}$, and $C_{f}$ are $500 \mu \mathrm{H}, 200 \mu \mathrm{H}$, and 50 $\mu \mathrm{F}$, respectively. $f_{s}$ and $f_{s w}$ are $10 \mathrm{kHz} . k_{p i}, k_{i i}, k_{p p l l}$, and $k_{i p l l}$ are $0.0325 \Omega, 32.5 \Omega / s, 2.5 \mathrm{rad} /(\mathrm{Vs})$, and $250 \mathrm{rad} /\left(\mathrm{Vs}^{2}\right)$, respectively. $i_{g d}^{r e f}$ and $i_{g q}^{r e f}$ are $25 \mathrm{~A}$ and $0 \mathrm{~A}$, respectively. In addition, the grid is emulated in an EGSTON $200 \mathrm{kVA}$ COMPISIO system unit, where $V_{g}$ and $\omega_{1}$ are $300 \mathrm{~V}$ and $314 \mathrm{rad} / \mathrm{s}$, respectively. A 1:1 Delta-Wye transformer provides galvanic isolation between the VSC and the grid emulator. Electrical measurements (i.e., $i_{c a b c}, v_{a b c}$, and $i_{g a b c}$ ) are captured with a Tektronix MSO3014 and exported into an OP5600 realtime simulator. The current controller and the PLL are directly implemented in the VSC and achieved on a Xilix Zynq 7030based processor, but critical time components are implemented as FPGA Xilinx Virtex5 blocks. The current references are sent in real-time by the OP5600 real-time simulator via a high speed fiber optic link. In addition, the grid emulator (i.e., the grid voltage reference $v_{g a b c}^{r e f}$ and the multi-tone voltage perturbation $v_{g a b c}^{\text {pert }}$ ) is implemented in Matlab/Simulink and executed on the real-time simulator. Based on the measured $v_{a b c}$ and $i_{g a b c}$, the $d q$-domain IFRs of the VSC (i.e., $\mathbf{Z}_{\mathbf{C C C}}^{\text {mea }}$ ) can be extracted using the FFT in the Matlab post-processing code [48].

2) Experimental Results: A multi-tone voltage perturbation $v_{g a b c}^{\text {pert }}$ with 28 frequency components logarithmically distributed in the frequency range $[1,5000] \mathrm{Hz}$ is injected into grid voltage reference $v_{g a b c}^{r e f}$. The overall perturbation 


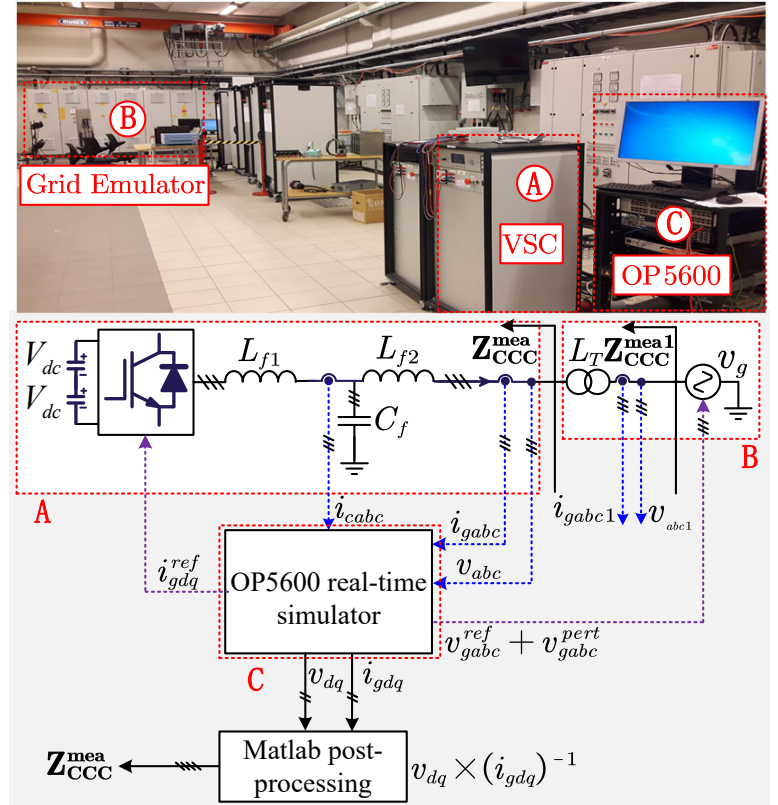

Fig. 9. The picture and single-line diagram of the PHiL-based experimental platform in the Norwegian National Smart Grid Laboratory jointly operated by SINTEF Energy Research and NTNU.

magnitude is about $5 \%$ of grid voltage, so that it is low enough to keep the normal system operation during the perturbation injection but high enough to provide necessary signal-to-noise ratio. Figs. 10(a) and 10(b) show the snapshots of $v_{a b c}$ and $i_{g a b c}$ without and with performing the voltage perturbation injection, respectively. It can be observed that the voltage and current are slightly distorted during the injection. $\mathbf{Z}_{\mathbf{C C C}}^{\text {mea }}$ is then calculated based on the DFTs of the perturbed $v_{a b c}$ and $i_{g a b c}$, and its Bode diagram is plotted in Fig. 11. The measured Bode diagram has a good fit with the expected result, e.g., the negative-resistor feature of the $q q$-axis element in the low-frequency range. The measurement accuracy of the off-diagonal elements is poorer than that of the diagonal elements. In addition, the $d d$ and $q q$-axis elements of $\mathbf{Z}_{\mathbf{C C C}}^{\text {theo }}$ in Fig. 4(a) and those of $\mathbf{Z}_{\mathbf{C C C}}^{\mathrm{mea}}$ in Fig. 11 have the similar trends, which indicates the effectiveness of the frequency scanning result (Note that the circuit and controller parameters used in simulation and experiment are different.). Besides, the experimentally-measured Bode diagram in Fig. 11 is smoother than the theoretically-derived Bode diagram in Fig. 4 (i.e., the high-frequency phase angles of the diagonal elements of $\mathbf{Z}_{\mathbf{C C C}}^{\text {mea }}$ in Fig. 11 and those of $\mathbf{Z}_{\mathbf{C C C}}^{\text {theo }}$ in Fig. 4(a) slowly increase and quickly jump to $90^{\circ}$, respectively.), due to the unpredictable parasitic resistance in practice.

In contrast with the ideal isolation transformer in the simulation environment, the isolation transformer in the experiment can affect the high-frequency impedance measurements. The $70 \mathrm{kVA}, 400 \mathrm{~V}$ isolation transformer has $4.34 \%$ impedance, which accounts for $315.76 \mu \mathrm{H}$ equivalent inductance $L_{T}$. In order to visualize this effect, the grid voltage $v_{a b c 1}$ and grid current $i_{g a b c 1}$ in Fig. 9 are measured, based on which the IFRs determined by both the VSC and the isolation transformer are calculated, and the Bode diagram is plotted in

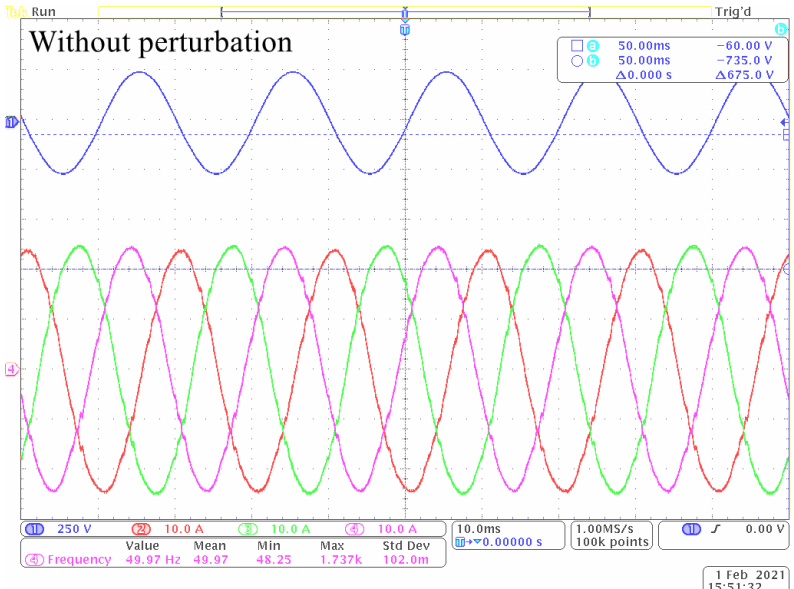

(a)

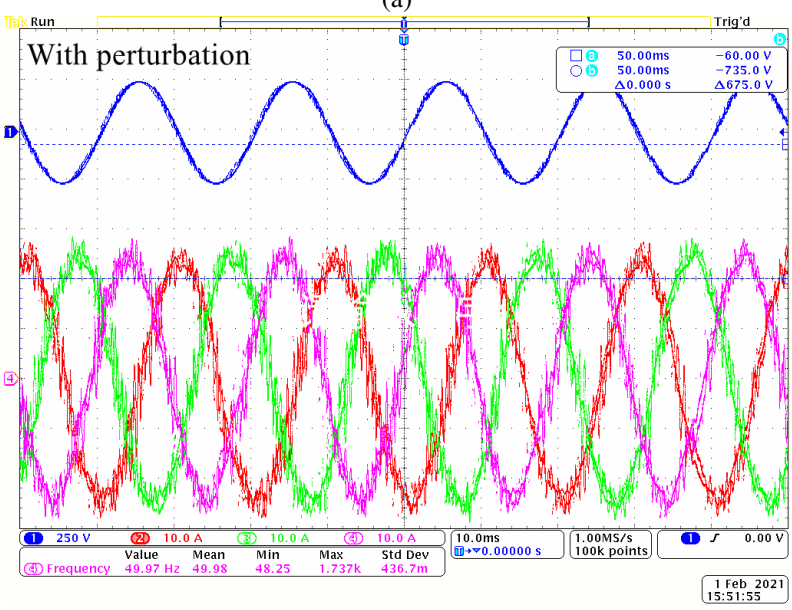

(b)

Fig. 10. Oscilloscope captures of $v_{a b c}$ and $i_{g a b c}$ (a) without and (b) with the multi-tone voltage perturbation injection.

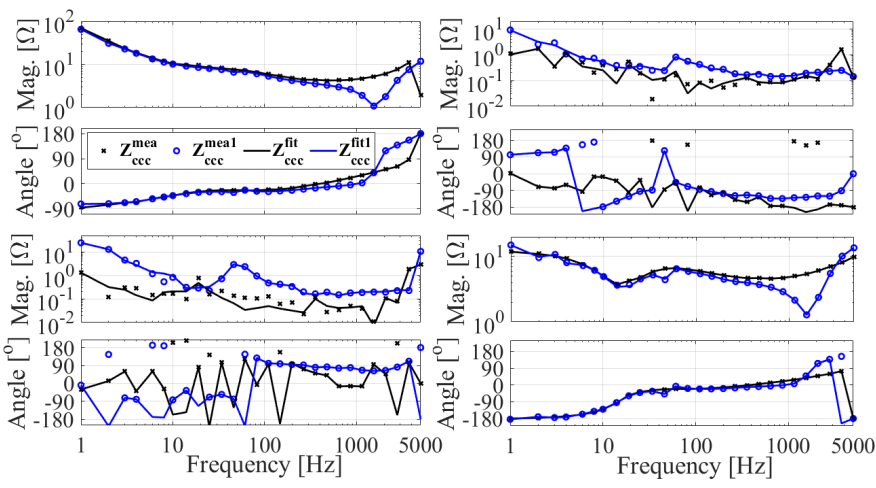

Fig. 11. Bode diagrams of the experimentally-measured $d q$-domain IFRs and the fitted results.

Fig. 11 as $\mathbf{Z}_{\mathbf{C C C}}^{\text {mea1 }}$. It can be seen that the isolation transformer mainly influences the high-frequency impedance feature of the VSC, whereas the low-frequency impedance feature is slightly changed.

In order to verify the effectiveness of the proposed parameters identification algorithm in (36) for the experimental results, the VF algorithm is applied on the $d d$-axis elements of $\mathbf{Z}_{\mathbf{C C C}}^{\text {mea }}$ and $\mathbf{Z}_{\mathbf{C C C}}^{\text {mea }}$, where the order varies from 8th to 23th. $E$ of the fitted transfer functions in form of (9) is then 
TABLE VII

IdENTIFIEd $L_{f 2}$ AND $L_{g}$ From Fig. 11 BASEd on the VF Algorithm

\begin{tabular}{ccccccc}
\hline \hline Fitting order & 8th & 11th & 14th & 17th & 20th & 23th \\
\hline$L_{f 2}[\mu \mathrm{H}]$ & 256.28 & 345.59 & 285.12 & 262.78 & 234.23 & 228.96 \\
$L_{g}[\mu \mathrm{H}]$ & 871.78 & 864.64 & 926.15 & 909.63 & 866.07 & 785.08 \\
\hline \hline
\end{tabular}

identified, based on which $L_{f 2}$ and $L_{g}=L_{f 2}+L_{T}$ are further identified from (36) and listed in Table VII. As the fitting order increases, the identified value of $L_{f 2}$ generally approaches the reference value of $L_{f 2}$ (i.e., $200 \mu \mathrm{H}$ ). Note that the actual value of $L_{f 2}$ in the laboratory may be not exactly the same as the reference value, due to manufacturing tolerance, operating condition variation, temperature fluctuation, and aging. Furthermore, the identified values of $L_{g}$ are larger than those of $L_{f 2}$, and the discrepancies reveal the transformer inductance and corresponding effect of the transformer on impedance measurement.

The application scenario of the proposed parameters identification method based on the VF algorithm should be emphasized here. In industrial practice, the IFRs can be obtained in several ways. In case 1 , the system planner can theoretically derive the impedance models of the VSCs as shown in (1) and (6), if internal control structures and parameters are provided by the vendors. In case 2, when detailed information of the VSCs is confidential for the system planner due to the industry secrecy and intellectual property protection, the vendors tend to deliver lookup tables which provide discrete IFRs of the VSCs, as shown in Figs. 3 and 4. In case 3, when blackbox simulation models are provided by the manufactures, the system planner can perform frequency scanning in commercial softwares, e.g., PSCAD/EMTDC and Matlab/Simulink, as shown in Figs. 6 and 7. In case 4, if both discrete IFRs and black-box simulation models are not provided by the vendors, the system planner can experimentally measure the IFRs of the VSCs by connecting these VSCs with a configurable strong grid, as shown in Fig. 9. The uncertainty and inaccuracy generally increase from case 1 to case 4 . This article focuses on the capability of the VF algorithm itself to identify internal parameters from IFRs, and the algorithm is especially efficient for cases 1, 2, and 3, as shown in Tables III and IV. Furthermore, the quantitative measurement noise can be properly dealt with based on an adaptive order selection scheme of the VF algorithm, as shown in Table VI. However, compared with cases 1,2, and 3, the impedance measurement and corresponding parameters identification using a real VSC in case 4 are more challenging, due to various unpredictable factors (e.g., variation of $L C L$ parameters, parasitic resistance, effect of isolation transformer, and accuracy of sensors). How to eliminate the adverse effects of these unpredictable factors and improve the accuracy of the impedance measurement results of a real VSC are out of scope of our article, and can be found in [26], [27], [29], [30].

\section{CONCLUSION}

This article presents a VF algorithm-based robust parameters identification method, which is able to identify circuit and controller parameters of the grid-connected VSCs based on the measured $d q$-domain IFRs. The proposed parameters identification method can be used when internal parameters are missing due to intellectual property right or filter parameters variation caused by operating condition change, temperature fluctuation, and aging. The identification accuracy is dependent on three factors, i.e., the measurement accuracy of the $d q$-domain IFRs, the order of the fitted transfer function, and the Pade approximation of the digital time delay. The impedance measurement accuracy can be improved using delicate devices such as frequency spectrum analyzer. The appropriate order of the fitted transfer function can be selected in a trial-and-error way. In addition, the corresponding Pade approximation should be established according to the order of the fitted transfer function. Furthermore, the effect of measurement noise on identification accuracy can be mitigated by increasing the order of the fitted transfer function. The OPAL-RT-based real-time simulation verification results show that the proposed parameters identification method helps to re-tune controller parameters of the gray-box VSC to mitigate instability phenomena under weak grid conditions. The PHiL-based experimental validation results show that the VF algorithm can be applied on a physical VSC in the laboratory, where unpredictable influence factors (e.g., variation of $L C L$ parameters, parasitic resistance, effect of isolation transformer, and accuracy of sensors) may be involved.

\section{APPENDIX}

The transfer function matrices in (1) and (6) are shown as follows.

$\mathbf{Z}_{L_{f 1}}=\left[\begin{array}{cc}s L_{f 1} & -\omega_{1} L_{f 1} \\ \omega_{1} L_{f 1} & s L_{f 1}\end{array}\right] \quad \mathbf{Z}_{L_{f 2}}=\left[\begin{array}{cc}s L_{f 2} & -\omega_{1} L_{f 2} \\ \omega_{1} L_{f 2} & s L_{f 2}\end{array}\right]$
$\mathbf{Z}_{C_{f}}=\left[\begin{array}{cc}\frac{s}{\left(s^{2}+\omega_{1}^{2}\right) C_{f}} & \frac{\omega_{1}}{\left(s^{2}+\omega_{1}^{2}\right) C_{f}} \\ -\frac{\omega_{1}}{\left(s^{2}+\omega_{1}^{2}\right) C_{f}} & \frac{s}{\left(s^{2}+\omega_{1}^{2}\right) C_{f}}\end{array}\right]$.

For the VSCs under GCC mode,

$$
\begin{aligned}
& \mathbf{Y}_{\mathbf{g c c}}^{\mathbf{c}}=\left(\left(\mathbf{Z}_{\mathbf{L}_{\mathrm{f} 1}^{-1}}^{-1} \mathbf{Z}_{\mathbf{C}_{\mathbf{f}}}^{-1}\right)^{-1}+\mathbf{Z}_{\mathbf{L}_{\mathbf{f} 2}}\right)^{-1} \\
& \mathbf{Y}_{\mathbf{g c c}}^{\mathbf{g}}=\left(\mathbf{Z}_{\mathbf{L} 2}\left(\mathbf{I}+\left(\mathbf{Z}_{\mathbf{L}_{\mathbf{f} 2}}^{-1}+\mathbf{Z}_{\mathbf{C}_{\mathbf{f}}}^{-1}\right) \mathbf{Z}_{\mathbf{L}_{\mathbf{f} 1}}\right)\right)^{-1} .
\end{aligned}
$$

For the VSCs under CCC mode,

$$
\mathbf{Y}_{\mathbf{c c c}}^{\mathrm{c}}=\mathrm{Y}_{\mathbf{c c c}}^{\mathrm{g}}=\mathrm{Z}_{\mathrm{L}_{\mathrm{f} 1}^{-1}}^{-}
$$

In addition,

$$
\mathbf{G}_{\mathbf{d e l}}=\left[\begin{array}{cc}
G^{\text {del }} & 0 \\
0 & G^{\text {del }}
\end{array}\right]=\left[\begin{array}{cc}
e^{-1.5 T_{s} s} & 0 \\
0 & e^{-1.5 T_{s} s}
\end{array}\right],
$$

where $T_{s}$ is the sampling time.

$$
\mathbf{G}_{\mathbf{c i}}=\left[\begin{array}{cc}
G^{c i} & 0 \\
0 & G^{c i}
\end{array}\right]=\left[\begin{array}{cc}
k_{p i}+\frac{k_{i i}}{s} & 0 \\
0 & k_{p i}+\frac{k_{i i}}{s}
\end{array}\right],
$$

where $k_{p i}$ and $k_{i i}$ are proportional and integrator coefficients of current controller, respectively. $V_{d c}$ is taken into account to design $k_{p i}$ and $k_{i i}$.

$\mathbf{G}_{\text {PLL }}^{\mathbf{i}}$ models the small-signal perturbation path from the system voltage to current in the controller $d-q$ frame, shown as

$$
\mathbf{G}_{\mathbf{P L L}}^{\mathbf{i}}=\left[\begin{array}{cc}
0 & I_{q}^{s} G_{P L L} \\
0 & -I_{d}^{s} G_{P L L}
\end{array}\right]
$$


where $I_{d}^{s}$ and $I_{q}^{s}$ are $d$-axis and $q$-axis components of threephase currents in system reference frame, respectively. $G_{P L L}$ is defined as

$$
G_{P L L}=\frac{k_{p p l l}+k_{i p l l} / s}{s+V_{d}^{s}\left(k_{p p l l}+k_{i p l l} / s\right)},
$$

where $k_{p p l l}$ and $k_{i p l l}$ are proportional and integrator coefficients of PLL, respectively. $V_{d}^{s}$ is the $d$-axis component of three-phase terminal voltages in system reference frame.

$\mathbf{G}_{\mathbf{P L L}}^{\mathbf{d}}$ models the small-signal perturbation path from the system voltage to duty cycle in the controller $d-q$ frame, shown as

$$
\mathbf{G}_{\mathbf{P L L}}^{\mathbf{d}}=\left[\begin{array}{cc}
0 & -D_{q}^{s} G_{P L L} \\
0 & D_{d}^{s} G_{P L L}
\end{array}\right],
$$

where $D_{d}^{s}$ and $D_{q}^{s}$ are $d$-axis and $q$-axis components of threephase duty cycles in system reference frame, respectively.

\section{REFERENCES}

[1] W. Zhou, Y. Wang, and Z. Chen, "A gray-box parameters identification method of voltage source converter using vector fitting algorithm," in Proc. IEEE 2019 10th International Conference on Power Electronics and ECCE Asia (ICPE 2019-ECCE Asia), pp. 2948-2955.

[2] F. Blaabjerg and K. Ma, "Future on power electronics for wind turbine systems," IEEE J. Emerg. Sel. Topics Power Electron., vol. 1, no. 3, pp. 139-152, Sep. 2013.

[3] F. Blaabjerg, Z. Chen, and S. B. Kjaer, "Power electronics as efficient interface in dispersed power generation systems," IEEE Trans. Power Electron., vol. 19, no. 5, pp. 1184-1194, Sep. 2004.

[4] Q.-C. Zhong, "Power-electronics-enabled autonomous power systems: Architecture and technical routes," IEEE Trans. Ind. Electron., vol. 64, no. 7, pp. 5907-5918, Jul. 2017.

[5] M. K. Bakhshizadeh, C. Yoon, J. Hjerrild, C. L. Bak, Ł. H. Kocewiak, F. Blaabjerg, and B. Hesselbæk, "The application of vector fitting to eigenvalue-based harmonic stability analysis," IEEE J. Emerg. Sel. Topics Power Electron., vol. 5, no. 4, pp. 1487-1498, Dec. 2017.

[6] M. K. Bakhshizadeh, F. Blaabjerg, J. Hjerrild, Ł. Kocewiak, and C. L. Bak, "Improving the impedance-based stability criterion by using the vector fitting method," IEEE Trans. Energy Convers., vol. 33, no. 4, pp. 1739-1747, Dec. 2018.

[7] M. Amin and M. Molinas, "A gray-box method for stability and controller parameter estimation in HVDC-connected wind farms based on nonparametric impedance," IEEE Trans. Ind. Electron., vol. 66, no. 3, pp. 1872-1882, Mar. 2019.

[8] W. Zhou, Y. Wang, and Z. Chen, "Impedance-decoupled modelling method of multi-port transmission network in inverter-fed power plant," IEEE Trans. Ind. Appl., vol. 56, no. 1, pp. 611-621, Jan./Feb. 2020.

[9] W. Zhou, Y. Wang, P. Cai, and Z. Chen, "A gray-box impedance reshaping method of grid-connected inverter for resonance damping," in Proc. IEEE 2019 10th International Conference on Power Electronics and ECCE Asia (ICPE 2019-ECCE Asia), pp. 2660-2667.

[10] D. Martin and E. Santi, "Autotuning of digital deadbeat current controllers for grid-tie inverters using wide bandwidth impedance identification," IEEE Trans. Ind. Appl., vol. 50, no. 1, pp. 441-451, Jan./Feb. 2014.

[11] S. Mukherjee, V. R. Chowdhury, P. Shamsi, and M. Ferdowsi, "Model reference adaptive control based estimation of equivalent resistance and reactance in grid-connected inverters," IEEE Trans. Energy Convers., vol. 32, no. 4, pp. 1407-1417, Dec. 2017.

[12] T.-F. Wu, M. Misra, Y.-Y. Jhang, Y.-H. Huang, and L.-C. Lin, "Direct digital control of single-phase grid-connected inverters with LCL filter based on inductance estimation model," IEEE Trans. Power Electron., vol. 34, no. 2, pp. 1851-1862, Feb. 2019.

[13] S. Neshvad, S. Chatzinotas, and J. Sachau, "Wideband identification of power network parameters using pseudo-random binary sequences on power inverters," IEEE Trans. Smart Grid, vol. 6, no. 5, pp. 2293-2301, Sep. 2015.

[14] J. Koppinen, J. Kukkola, and M. Hinkkanen, "Plug-in identification method for an LCL filter of a grid converter," IEEE Trans. Ind. Electron., vol. 65 , no. 8, pp. 6270-6280, Aug. 2018.
[15] V. Valdivia, A. Lazaro, A. Barrado, P. Zumel, C. Fernandez, and M. Sanz, "Black-box modeling of three-phase voltage source inverters for system-level analysis," IEEE Trans. Ind. Electron., vol. 59, no. 9, pp. 3648-3662, Sep. 2012.

[16] Y.-C. Cho, K.-Y. Choi, and R.-Y. Kim, "Adaptive damping scheme of LCL filter resonance under inductance variation for a single-phase gridconnected inverter," in Proc. 2015 IEEE 9th International Conference on Power Electronics and ECCE Asia (ICPE-ECCE Asia), pp. 978-983.

[17] W. Zhou, Y. Wang, and Z. Chen, "Frequency and temperature-dependent power cable modelling for stability analysis of grid-connected inverter," in Proc. 2018 IEEE 4th Southern Power Electronics Conference (SPEC), pp. $1-8$.

[18] A. Vidal, A. G. Yepes, F. D. Freijedo, J. Malvar, Ó. López, and J. DovalGandoy, "A technique to estimate the equivalent loss resistance of gridtied converters for current control analysis and design," IEEE Trans. Power Electron., vol. 30, no. 3, pp. 1747-1761, Mar. 2015.

[19] A. Vidal, A. G. Yepes, F. D. Freijedo, O. Lopez, J. Malvar, F. Baneira, and J. Doval-Gandoy, "A method for identification of the equivalent inductance and resistance in the plant model of current-controlled gridtied converters," IEEE Trans. Power Electron., vol. 30, no. 12, pp. 72457261, Dec. 2015.

[20] M. Esparza, J. Segundo, C. Gurrola-Corral, N. Visairo-Cruz, E. Barcenas, and E. Barocio, "Parameter estimation of grid connected VSC using the extended harmonic domain," IEEE Trans. Ind. Electron., vol. 66 , no. 8, pp. 6044-6054, Aug. 2019.

[21] Z. Liu, H. Wu, W. Jin, B. Xu, Y. Ji, and M. Wu, "Two-step method for identifying photovoltaic grid-connected inverter controller parameters based on the adaptive differential evolution algorithm," IET Gener. Transm. Distrib., vol. 11, no. 17, pp. 4282-4290, Nov. 2017.

[22] W. Zhou, R. E. Torres-Olguin, Y. Wang, and Z. Chen, "A graybox hierarchical oscillatory instability source identification method of multiple-inverter-fed power systems," IEEE J. Emerg. Sel. Topics Power Electron., Early Access.

[23] M. Céspedes and J. Sun, "Online grid impedance identification for adaptive control of grid-connected inverters," in Proc. 2012 IEEE Energy Conversion Congress and Exposition (ECCE), pp. 914-921.

[24] M. Cespedes and J. Sun, "Adaptive control of grid-connected inverters based on online grid impedance measurements," IEEE Trans. Sustain. Energy, vol. 5, no. 2, pp. 516-523, Apr. 2014.

[25] A. Riccobono, E. Liegmann, A. Monti, F. C. Dezza, J. Siegers, and E. Santi, "Online wideband identification of three-phase AC power grid impedances using an existing grid-tied power electronic inverter," in Proc. 2016 IEEE 17th Workshop on Control and Modeling for Power Electronics (COMPEL), pp. 1-8.

[26] T. Roinila and T. Messo, "Online grid-impedance measurement using ternary-sequence injection," IEEE Trans. Ind. Appl., vol. 54, no. 5, pp. 5097-5103, Sep./Oct. 2018.

[27] R. Luhtala, T. Roinila, and T. Messo, "Implementation of real-time impedance-based stability assessment of grid-connected systems using MIMO-identification techniques," IEEE Trans. Ind. Appl., vol. 54, no. 5, pp. 5054-5063, Sep./Oct. 2018.

[28] A. Riccobono, M. Mirz, and A. Monti, "Noninvasive online parametric identification of three-phase AC power impedances to assess the stability of grid-tied power electronic inverters in LV networks," IEEE J. Emerg. Sel. Topics Power Electron., vol. 6, no. 2, pp. 629-647, Jun. 2018.

[29] T. Roinila, T. Messo, and E. Santi, "MIMO-identification techniques for rapid impedance-based stability assessment of three-phase systems in DQ domain," IEEE Trans. Power Electron., vol. 33, no. 5, pp. 40154022, May 2018.

[30] T. Roinila, T. Messo, R. Luhtala, R. Scharrenberg, E. de Jong, A. Fabian, and Y. Sun, "Hardware-in-the-loop methods for real-time frequencyresponse measurements of on-board power distribution systems," IEEE Trans. Ind. Electron., vol. 66, no. 7, pp. 5769-5777, Jul. 2019.

[31] V. Valdivia, A. Lázaro, A. Barrado, P. Zumel, C. Fernández, and M. Sanz, "Impedance identification procedure of three-phase balanced voltage source inverters based on transient response measurements," IEEE Trans. Power Electron., vol. 26, no. 12, pp. 3810-3816, Dec. 2011.

[32] H. Liu, X. Xie, and W. Liu, "An oscillatory stability criterion based on the unified $d q$-frame impedance network model for power systems with high-penetration renewables," IEEE Trans. Power Syst., vol. 33, no. 3, pp. 3472-3485, May 2018.

[33] H. Liu and X. Xie, "Impedance network modeling and quantitative stability analysis of sub-/super-synchronous oscillations for large-scale wind power systems," IEEE Access, vol. 6, pp. 34 431-34 438, 2018. 
[34] W. Zhou, Y. Wang, and Z. Chen, "Reduced-order modelling method of grid-connected inverter with long transmission cable," in Proc. 2018 IEEE 44th Annual Conference of the IEEE Industrial Electronics Society (IECON), pp. 4383-4389.

[35] A. Rygg and M. Molinas, "Apparent impedance analysis: A small-signal method for stability analysis of power electronic-based systems," IEEE J. Emerg. Sel. Topics Power Electron., vol. 5, no. 4, pp. 1474-1486, Dec. 2017.

[36] W. Zhou, R. E. Torres-Olguin, Y. Wang, and Z. Chen, "DQ impedancedecoupled network model-based stability analysis of offshore wind power plant under weak grid conditions," IET Power Electron., vol. 13, no. 13, pp. 2715-2729, Oct. 2020.

[37] B. Wen, D. Boroyevich, R. Burgos, P. Mattavelli, and Z. Shen, "Analysis of D-Q small-signal impedance of grid-tied inverters," IEEE Trans. Power Electron., vol. 31, no. 1, pp. 675-687, Jan. 2016.

[38] A. Rygg, M. Molinas, C. Zhang, and X. Cai, "On the equivalence and impact on stability of impedance modeling of power electronic converters in different domains," IEEE J. Emerg. Sel. Topics Power Electron., vol. 5, no. 4, pp. 1444-1454, Dec. 2017.

[39] S. Shah and L. Parsa, "Impedance modeling of three-phase voltage source converters in DQ, sequence, and phasor domains," IEEE Trans. Energy Convers., vol. 32, no. 3, pp. 1139-1150, Sep. 2017.

[40] B. Gustavsen and A. Semlyen, "Rational approximation of frequency domain responses by vector fitting," IEEE Trans. Power Del., vol. 14, no. 3, pp. 1052-1061, Jul. 1999.

[41] W. Zhou, Y. Wang, R. E. Torres-Olguin, and Z. Chen, "Effect of reactive power characteristic of offshore wind power plant on low-frequency stability," IEEE Trans. Energy Convers., vol. 35, no. 2, pp. 837-853, Jun. 2020.

[42] Y. Wang, X. Wang, F. Blaabjerg, and Z. Chen, "Harmonic instability assessment using state-space modeling and participation analysis in inverter-fed power systems," IEEE Trans. Ind. Electron., vol. 64, no. 1, pp. 806-816, Jan. 2017.

[43] D. Yang, X. Ruan, and H. Wu, "Impedance shaping of the grid-connected inverter with LCL filter to improve its adaptability to the weak grid condition," IEEE Trans. Power Electron., vol. 29, no. 11, pp. 57955805, Nov. 2014.

[44] W. Zhou, Y. Wang, R. E. Torres-Olguin, and Z. Chen, "DQ impedance reshaping of three-phase power-controlled grid-connected inverter for lowfrequency stability improvement under weak grid condition," in Proc. 2020 IEEE 12th Annual Conference of the IEEE Energy Conversion Congress and Exposition (ECCE), pp. 1678-1685.

[45] L. Harnefors, X. Wang, S.-F. Chou, M. Bongiorno, M. Hinkkanen, and M. Routimo, "Asymmetric complex-vector models with application to VSC-grid interaction," IEEE J. Emerg. Sel. Topics Power Electron., vol. 8, no. 2, pp. 1911-1921, Jun. 2020.

[46] S. Kouro, P. Cortés, R. Vargas, U. Ammann, and J. Rodríguez, "Model predictive control-a simple and powerful method to control power converters," IEEE Trans. Ind. Electron., vol. 56, no. 6, pp. 1826-1838, Jun. 2009.

[47] S. Vazquez, J. Rodriguez, M. Rivera, L. G. Franquelo, and M. Norambuena, "Model predictive control for power converters and drives: Advances and trends," IEEE Trans. Ind. Electron., vol. 64, no. 2, pp. 935-947, Feb. 2017.

[48] A. Rygg, "Impedance-based methods for small-signal analysis of systems dominated by power electronics," Ph.D. dissertation, The Department of Engineering Cybernetics, Norwegian University of Science and Technology, Trondheim, Norway, 2018.

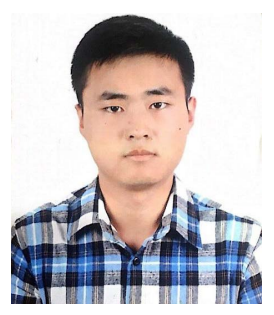

Weihua Zhou (S'18-M'20) was born in Anhui, China, in 1993. He received the B.Eng. and M.Sc. degrees in electrical engineering from the School of Automation, Northwestern Polytechnical University, Xi' an, China, in 2014 and 2017, respectively, and the Ph.D. degree in electrical engineering from the Department of Energy Technology, Aalborg University, Aalborg, Denmark, in 2020

He is currently a Postdoctoral Research Fellow with the Department of Electrical Engineering, University of Leuven (KU Leuven), Belgium, and also with EnergyVille, Genk, Belgium. From November 2015 to May 2016, he was a Junior Research Assistant at the Department of Mechanical and Automation Engineering, the Chinese University of Hong Kong, Hong Kong. From August 2020 to November 2020, he was a visiting Ph.D. student at the Department of Marine Technology, the Norwegian University of Science and Technology, Trondheim, Norway. His research interests include modeling and control of grid-connected converters, impedance-based stability analysis and instability source identification of power electronic-based power systems.

Dr. Zhou was the recipient of the Best Paper Award at the 6th International Conference on Smart Grids (icSmartGrid) cosponsored by IEEE Industry Application Society in 2018.

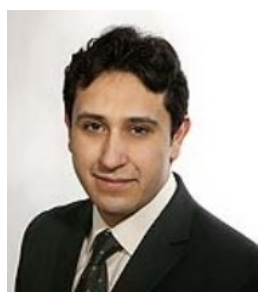

Raymundo E. Torres-Olguin received the B.Sc. degree in electromechanical engineering from the University of San Luis Potosí, Mexico, in 2004, M.Sc. degree in control and dynamical systems from the Applied Mathematics Department, Research Institute of Science and Technology of San Luis Potosí (IPICYT), Mexico, in 2006, and Ph.D. degree in electric power engineering from the Norwegian University of Science and Technology, Norway, in 2013

From 2012, he has worked as a research scientist in SINTEF Energy Research Institute, Trondheim, Norway. His main research interests include control of power electronics for the integration of renewable resources, dc transmission, and microgrids.

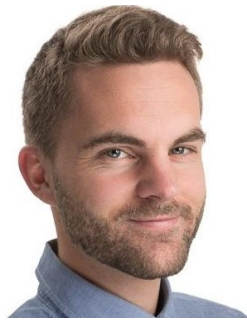

Fredrik Göthner was born in Oslo, Norway, in 1992. He received the M.Sc. degree in electrical power engineering in 2017 from the Norwegian University of Science and Technology, Trondheim, Norway, where he is currently working toward the $\mathrm{Ph} . \mathrm{D}$. degree on the control of converters in microgrids. His main research interests include control of power electronics and issues related to stability and power quality in microgrids.

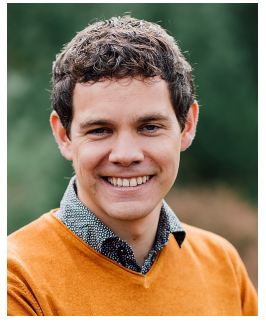

Jef Beerten (S'07-M'13-SM'19) received the M.Sc. and $\mathrm{Ph} . \mathrm{D}$. degrees in electrical engineering from the University of Leuven (KU Leuven), Belgium, in 2008 and 2013, respectively. Currently, he is an Assistant Professor with KU Leuven and EnergyVille.

In 2011, he was a visiting researcher at the KTH Royal Institute of Technology, Stockholm, Sweden, for three months. From April 2014 to March 2015, he was a visiting Postdoctoral Researcher at the Norwegian University of Science and Technology, Trondheim, Norway. His research interests include future power system dynamics, modeling, and control.

Dr. Beerten was the first winner of the ABB Research Award in Honor of Hubertus von Gruenberg in 2016, and received the KBVE/SRBE Robert Sinave Award and the Prix Paul Caseau from the Institut de France-EDF Foundation for his Ph.D. thesis on modeling and control of DC grids. Dr. Beerten is an active member of both the IEEE and CIGRE. 


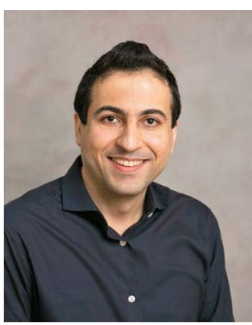

Mehdi Karbalaye Zadeh (S'12-M'16) received the M.Sc. degree in electrical engineering from the University of Tehran, Tehran, Iran, in 2010, and the $\mathrm{Ph} . \mathrm{D}$. degree in electrical engineering from the Norwegian University of Science and Technology (NTNU), Trondheim, Norway, in 2016.

From 2016 to 2017, he was with the power electronics industry, working on the development of battery charging systems. In 2017, he joined the Marine Technology Centre at NTNU, where he is currently an Associate Professor of Hybrid Power Systems and the director of the Marine Electrification Research Laboratory. His main research interests include ship electrification for low-emission and autonomous shipping, onboard DC power systems, and offshore renewable energy systems

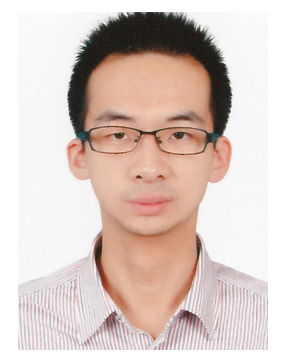

Yanbo Wang (S'15-M'17-SM'19) received Ph.D degree in electrical engineering at the Department of Energy Technology, Aalborg University, Aalborg, Denmark, in 2017, where he is currently an Assistant Professor.

From June 2016 to October 2016, he was a visiting Ph.D. student in Power System Research Group of the Department of Electrical and Computer Engineering, University of Manitoba, Winnipeg, MB Canada. His research interests include distributed power generation system, wind power system, microgrid, as well as operation and control technologies of power electronicdominated power system.

Dr. Wang's paper on Distributed Power System received the First Prize Paper Award of the 6th International Conference of Smart Grid cosponsored by IEEE Industry Application Society in 2018. He received the Best Session Paper Award at the annual conference of the IEEE Industrial Electronics Society in 2015 in Japan.

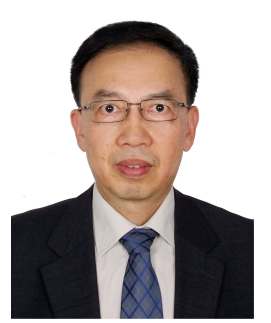

Zhe Chen (M'95-SM'98-F'19) received the B.Eng. and M.Sc. degrees in electrical engineering from Northeast China Institute of Electric Power Engineering, Jilin City, China, M.Phil. degree in power electronic from Staffordshire University, England, and $\mathrm{Ph} . \mathrm{D}$. degree in electrical engineering from University of Durham, England.

Dr. Chen is a full Professor with the Department of Energy Technology, Aalborg University, Aalborg, Denmark. He is the leader of Wind Power System Research program at the Department of Energy Technology, Aalborg University and the Danish Principle Investigator for Wind Energy of Sino-Danish Centre for Education and Research. His research areas are power systems, power electronics, and electric machines. His main current research interests are wind energy and modern power systems. He has led many research projects and has more than 500 publications in his technical fields. 